\title{
Genome-wide identification and transcript analysis of TCP transcription factors in grapevine
}

\author{
Xiangpeng Leng ${ }^{1 * \dagger}$, Hongru Wei ${ }^{1 \dagger}$, Xiaozhao Xu', Sandip A. Ghuge ${ }^{2}$, Dongjie Jia', Gengsen Liu', \\ Yongzhang Wang ${ }^{1}$ and Yongbing Yuan ${ }^{1 *}$
}

\begin{abstract}
Background: The plant-specific TCP transcription factors play different functions in multiple processes of plant growth and development. TCP family genes have been identified in several plant species, but no comprehensive analysis of the TCP family in grapevine has been undertaken to date, especially their roles in fruit development.

Results: A total of 18 non-redundant grapevine TCP (VVTCP) genes distributing on 11 chromosomes were identified. Phylogenetic and structural analysis showed that VVTCP genes were divided into two main classes - class I and class II. The Class II genes were further classified into two subclasses, the CIN subclass and the CYC/TB1 subclass. Segmental duplication was a predominant duplication event which caused the expansion of VVTCP genes. The cis-acting elements analysis and tissue-specific expression patterns of VVTCP genes demonstrated that these VVTCP genes might play important roles in plant growth and development. Expression patterns of $V V T C P$ genes during fruit development and ripening were analyzed by RNA-Seq and qRT-PCR. Among them, 11 VVTCP genes were down-regulated during different fruit developmental stages, while only one VVTCP genes were up-regulated, suggesting that most VVTCP genes were probably related to early development in grapevine fruit. Futhermore, the expression of most VVTCP genes can be inhibited by drought and waterlogging stresses.
\end{abstract}

Conclusions: Our study establishes the first genome-wide analysis of the grapevine TCP gene family and provides valuable information for understanding the classification and functions of the TCP genes in grapevine.

Keywords: Grapevine, TCP transcription factors, Fruit development and ripening, Expression profiles analysis

\section{Background}

TCP proteins are a small family of plant-specific transcription factors and play important roles in multiple processes of plant growth and development by regulating cell growth and proliferation [1-3]. TCP transcription factors were named after four founding members: TEOSINTE BRANCHED1 (TB1) from Zea mays, CYCLOIDEA (CYC) from Antirrhinum majus, PROLIFERATING CELL NUCLEAR ANTIGEN FACTOR 1 and 2 (PCF1 and PCF2) from Oryza sativa [4-6]. TCP proteins are featured by the TCP domain, a highly conserved 59-residue-long basic

\footnotetext{
*Correspondence: lengpeng2008@163.com; yyb@qau.edu.cn

${ }^{+}$Xiangpeng Leng and Hongru Wei contributed equally to this work.

'Qingdao Key Lab of Modern Agriculture Quality and Safety Engineering,

College of Horticulture, Qingdao Agricultural University, Changcheng Road

700, Qingdao 266109, People's Republic of China
}

Full list of author information is available at the end of the article helix-loop-helix (bHLH) structure at the N-terminus, which is associated with DNA binding, protein-protein interaction and protein nuclear localization [7]. Based on the sequence features and homology of the TCP domains, TCP family members were classified into two subfamilies: Class I (represented by the PCF proteins) and class II (represented by CYC and TB1) [2, 8]. The most noticeable difference between these two subfamilies is that class I members show a four-amino acids deletion in the basic region of the TCP domain [2]. The class II TCP members are further subdivided into two subclades (CIN and CYC/ TB1) based on the difference among their TCP domain. Furthermore, several class II members have an argininerich motif ( $\mathrm{R}$ domain) with unknown functions, which is hypothesized to be involved in facilitation of proteinprotein interaction $[1,2]$.

(c) The Author(s). 2019 Open Access This article is distributed under the terms of the Creative Commons Attribution 4.0 International License (http://creativecommons.org/licenses/by/4.0/), which permits unrestricted use, distribution, and reproduction in any medium, provided you give appropriate credit to the original author(s) and the source, provide a link to the Creative Commons license, and indicate if changes were made. The Creative Commons Public Domain Dedication waiver (http://creativecommons.org/publicdomain/zero/1.0/) applies to the data made available in this article, unless otherwise stated. 
Increasing evidences show that TCP transcription factors play versatile functions in multiple physiological and biological processes during plant growth and development, such as branching [9, 10], leaf morphogenesis $[11,12]$, flower development $[13,14]$, seed germination $[15,16]$, hormone pathways $[17,18]$ and response to environmental stress [19]. In Arabidopsis, AtTCP14 and AtTCP15 have been shown to regulate embryonic growth during seed germination by gibberellin signaling pathway [16]. They also could regulate leaf shape and internode length by promoting cell proliferation [12]. AtTCP16 is observably expressed in developing microspores, and its down-regulation generated $50 \%$ abnormal pollen in transgenic plants [20]. Recently, strong experimental evidence supports that class I members of TCP proteins could be implicated in fruit development and ripening $[21,22]$. Three tomato TCP genes (SlTCP12, SITCP15 and SITCP18) are preferentially expressed in the tomato fruit and their expressions are regulated by ripening-related transcription factor, such as RIPENING INHIBITOR (RIN) and COLORLESS NON-RIPENING $(C N R)$ [21]. The strawberry FaTCP11 gene participates in ripening-related processes and regulates flavan-3-ols synthesis [23].

The functions of most class II members of TCP family have been elucidated. For example, the TB1 gene involves in the fate of maize axillary meristems [5] and the $C Y C$ gene affects the asymmetry, size and cell types of petals and stamens in Antirrhinum flower [4]. In Arabidopsis, AtTCP18 and AtTCP12, two homologs of TB1, are involved in suppressing bud outgrowth [9]. The tomato orthologs SlTCP9 (SlBRC1a) and SlTCP7 (SlBRC1b) also show similar functions in axillary bud initiation and outgrowth [24]. AtTCP1, the homolog of CYC, mediates plant growth and development by regulating the expression levels of brassinosteroid biosynthesis gene DWARF4 [25]. Five CIN-like genes including AtTCP2, AtTCP3, AtTCP4, AtTCP10 and AtTCP24 were targeted by miR319 and have been shown to be involved in regulating leaf and flower development [14, 26-28]. Moreover, AtTCP3 can increase flavonoid biosynthesis by interacting with R2R3MYB proteins [29] and dominant-negative variant of AtTCP3 leads to shorter and crinkled siliques [30]. Transient over-expression of FvTCP9 in strawberry fruits dramatically promotes the expression of a series of genes involved in fruit color and aroma metabolism, suggesting that class II member of TCP family could be participated in fruit development and ripening processes [31].

To date, a number of TCP family members have been characterized in both dicots and monocots with the completion of entire genome, such as Arabidopsis [32], tomato [21], apple [33], strawberry [31], bamboo [34] and switchgrass [35]. However, little is known about the TCP family in grapevine [36], which is one of the most important fruit crop growing around the world with great nutritive and commercial value [37-39]. Due to the important roles of TCP transcription factors during plant growth and development, we performed for the comprehensive analysis of the $V v T C P$ transcription factor family in grapevine. In the present study, 18 non-redundant TCP genes were identified from grapevine and were subsequently performed a systematic analysis including chromosome location, phylogenetic relationships, gene structure, conserved motif and cis-acting elements. We further analyzed the expression of $V v T C P$ genes in diverse tissues, different stages of fruit development and ripening, as well as in response to hormones and stress treatment. This study provides reliable investigation of the $V v T C P$ gene family and facilitates further functional characterization of TCP members in grapevine.

\section{Methods}

\section{Identification of putative $V V T C P$ in grapevine}

Two different methods were peformed to identify and annotate TCP genes in grapevine genome. Firstly, the hidden Markov model (HMM) profile of the conserved TCP domain (PF03634) was downloaded from the Pfam database (http://pfam.janelia.org) and used to screen all grapevine proteins in the $12 \times$ coverage assembly of the $V$. vinifera PN40024 genome. Secondly, all Arabidopsis TCP protein sequences, which were downloaded from the Arabidopsis Information Resource (TAIR) database (http://www.arabidopsis.org), were used as queries to screen against grapevine genome database by using DNAtools software. Subsequently, all non-redundant VvTCP protein sequences were further verified for the presence of the TCP domain by screening against the Pfam (http://pfam.sanger.ac.uk/), InterProScan (http://www.ebi.ac.uk/Tools/pfa/iprscan/) and SMART (http://smart.embl-heidelberg.de/) database. The molecular weights (MW), isoelectric points (pI) and grand average of hydropathicity (GRAVY) of VvTCP proteins were calculated by the ExPasy website (https://web.expasy. org/protparam/). The subcellular location of VvTCP proteins was predicted by WoLF PSORT (http://www.genscript.com/psort/wolf_psort.html).

\section{Sequence alignment and phylogenetic analysis}

Sequences of the 24 Arabidopsis and 22 rice TCP proteins were retrieved from TAIR (https://www.arabidopsis.org/) and rice genome database (http://rice.plantbiology.msu. $\mathrm{edu} /$ ), respectively. The sequences of 30 tomato TCP family members were retrieved from the Solanaceae Genomics Network (https://solgenomics.net/). The sequences of 19 strawberry TCP family members were retrieved from PlantTFDB (http://planttfdb.cbi.pku.edu.cn/). The Antirrhinum $\mathrm{CYC}$ and maize TB1 were retrieved from NCBI database (https://www.ncbi.nlm.nih.gov/).

ClustalX 2.0 software was used to perform the multiple sequence alignments of the amino acid sequences 
of the TCP proteins of grapevine, Arabidopsis, rice, tomato and strawberry. An unrooted phylogenetic tree based on the full length protein sequences sequence alignments was constructed using MEGA 7.0 software and the neighbor-joining method with the following parameters: pairwise alignment, 1000 bootstrap replicates, Poisson correction model, uniform substitution rates and complete deletion. Moreover, another phylogenetic tree was also constructed using all protein sequences of TCP domain in grapevine for further analysis. The motif logos of the VvTCPs were generated by submitting the sequences to the MEME website (http://meme.nbcr.net/ meme/cgi-bin/meme.cgi). Below are the parameters of MEME used: maximum number of motifs, 20 ; minimum motif width, 6; and maximum motif width, 50 .

\section{Chromosomal location, gene structure, and duplication analysis}

All $V v T C P$ genes were mapped to grapevine chromosomes based on physical positions at the Grape Genome CRIBI website (http://genomes.cribi.unipd.it/) and the map was drawn using the MapInspect software. Accordingly, the cDNA sequences and their corresponding genomic DNA sequences of $V v T C P$ members were obtained from the grapevine genome, then the exon-intron organization were identified by comparing the coding sequences with their corresponding genomic sequences using the GSDS software (http://gsds.cbi. pku.edu.cn) [40]. Tandem duplicated genes were defined by checking their physical locations on individual chromosomes and were identified as adjacent paralogous on a grape chromosome, with no more than one intervening gene [41]. For synteny analysis, the synteny blocks were detected by MCScanX software (http:// chibba.pgml.uga.edu/mcscan2/), with the E-value set below $1 \times 10^{-5}$ taking reference from a previous study [42]. The diagrams were generated by the program Circos version 0.63 (http://circos.ca/) [43].

\section{In silico promoter analysis}

The promoter sequences of 1, $500 \mathrm{bp}$ upstream of the coding region of each $V v T C P$ genes were retrieved from the grapevine genome website CRIBI (http://genomes. cribi.unipd.it/). PlantCARE online program (http://bioinformatics.psb.ugent.be/webtools/plantcare/html/) were employed to search the putative cis-acting element [44].

\section{Expression profiles of $V v T C P s$ in various organs and different berry developmental stages}

The expression profiles of $V v T C P$ genes were determined in a Vitis vinifera cv 'Corvina' (clone48) gene expression atlas of various organs at different developmental stages. Microarray data were obtained from the NCBI gene expression omnibus (GEO) datasets under the series entry
GSE36128 (http://www.ncbi.nlm.nih.gov/geo/) [45]. The mean of expression value of each gene in all tissues/organs were analyzed and graphically represented using Multi Experiment Viewer (MeV) software [46]. The expression patterns of $V v T C P$ genes in fruit developmental stages were acquired from gene expression omnibus (GEO) database of NCBI (GSE77218), which measured using RNAsequencing (RNA-Seq) data [47]. Berries from 3 year old grapevine trees 'Fujiminori' ( $V$. vinifera $\times$ V. labrusca) were sampled in triplicate at the green fruit expanding (40DAF or DAF40), veraison (65DAF or DAF65), and ripe (90DAF or DAF90) stages throughout the growing season. Furthermore, expression analyses of $V v T C P$ genes in 10 different grapevine (Vitis vinifera) varieties at four berry development stages were based on RNA-seq data (accession numbers GSE62744 and GSE62745) downloaded from the NCBI GEO datasets [48]. The 10 varieties contained five red-skinned (Sangiovese, Barbera, Negro amaro, Refosco and Primitivo) and five white-skinned berries (Vermentino, Garganega, Glera, Moscato bianco and Passerina). Berries were sampled in triplicate at four developmental stages, the pea-sized berry stage at $20 \mathrm{~d}$ after flowering, the berries beginning to touch stage just prior to veraison (Pre_veraison), the berry-softening stage at the end of veraison (End_veraison), and the fully ripe berry stage at harvest.

\section{The expression of $V v T C P$ under stress condition}

To investigate the expression profiles of TCPs in response to different stress treatment $(\mathrm{Cu}$, salt, waterlogging and drought stress), grapevine RNA-seq data sets (SRA accession no. SRP070475 and SRP074162) were retrieved from NCBI GEO database (https://www.ncbi. nlm.nih.gov/geo/) or from published supplemental data sets [37, 49-51]. Two-year-old 'Summer Black' (hybrids of $V$. vinifera and $V$. labrusca) grapevine were used to investigate the expression of TCP genes in response to abiotic stresses. $\mathrm{Cu}$ stress of potted grapevine plants was simulated with $100 \mu \mathrm{M} \mathrm{CuSO}$ and salt stress was treated with $0.8 \% \mathrm{NaCl}[37,50]$. The control plantlets were similarly treated with distilled water. Waterlogging treatment were performed by immersing the plants to water for $48 \mathrm{~h}$ [51] and drought treatment was performed by withholding water 20 days [49]. Grapevine plantlets grown in the standard conditions were used as a control. All types of samples were three replicates and the third and fourth unfolded leaves from the shoot apex was collected from treatment and control groups during deep sequencing. The analysis of RNA-seq data was according to previous method [37] and the RPKM (Reads Per Kilobase per Million mapped reads) values were used to estimate the gene expression level. The heatmap of TCP genes was exhibited using $\mathrm{R}$ software (http:// www.bioconductor.org/). 


\section{Plant growth condition and gene expression analysis using qRT-PCR}

Four-years-old 'Fujiminori' grapevine trees, grown in the standard field conditions at the Qingdao Agricultural University fruit farm, Qingdao, China, were chosen as the experimental material. To investigate gene expression profiles of TCP genes during berry development and ripening, grapevine berry samples were also collected at three time points: the green fruit expanding stage (40 DAF), veraison (70 DAF) and ripe/harvest stages (90 DAF) throughout the growing season. All samples were collected in triplicate from each of the sampling points. The samples were immediately frozen in liquid nitrogen and stored at $-80^{\circ} \mathrm{C}$ until use.

A total of $200 \mathrm{mg}$ of the grapevine tissues were used from above mentioned samples for total RNA isolation using the modified CTAB method [38], followed by DNaseI (Tiangen, Beijing, China) digestion to eliminate any contaminating DNA. For qRT-PCR analysis, the first-strand cDNAs was synthesized from the $1 \mu \mathrm{g}$ RNA using a PrimeScriptTM RT Reagent Kit (TaKaRa, Dalian, China) according to the manufacturer's instructions. Expression pattern of various genes obtained from Microarray data was validated by qRT-PCR. The primers used for the qRT-PCR were designed using Primer 3.0 online and details of the primer sequences were presented in Additional file 2: Table S1. The grapevine housekeeping gene Actin (AB073011) was used as the internal control. The qRT-PCR was peformed using SYBR ${ }^{\bullet}$ Premixm Ex $\mathrm{Taq}^{\mathrm{TM}}$ (TaKaRa, Japan) with the Applied Biosystems 7500 Real-Time PCR System. All the experiments were carried out with three biological replicates. The $2^{-\Delta \Delta C T}$ method was used to estimate the relative expression level [52].

\section{Subcellular localization of grapevine TCP genes}

Based on the grapevine genome and public NCBI database, the full coding sequences of three randomly selected $V v T C P$ genes were PCR-amplified with highfidelity HS polymerase (TaKaRa Biotechnology, Dalian, China) using the primers listed in Additional file 2: Table S1. To construct green fluorescent protein (GFP)-tagged VvTCP, the three cloned $V v T C P$ genes (35S, VvTCP2-GFP, 35S: VvTCP3-GFP and 35S: VvTCP18-GFP) were inserted into the pCAMBIA1300 vector, respectively. After electroporation of these construction into Agrobacterium tumefaciens EHA105, the transformed bacterial cells were activated and infected into the leaf tissue of Nicotiana benthamiana as previously described [53]. The transient expression of VvTCPs-GFP was observed $72 \mathrm{~h}$ later using a laser confocal microscope (Zeiss LSM700, Germany), the mCherry-labelled nuclear marker (NF-YA4-mCherry) was used to visualize the nucleus.

\section{Results}

Identification of TCP gene family in grapevine

In order to identify and obtain the TCP genes in grapevine genome, the BLAST searches were performed at NCBI and other public databases. Subsequently, the HMM profile was employed to perform a global search of the grapevine genome (http://genomes.cribi.unipd.it/ grape/). After removing the redundant sequences, 18 non-redundant $V v T C P$ genes were identified and mapped onto 11 out of 19 grapevine chromosomes (Additional file 1: Figure S1). Further, $18 V v T C P$ genes were annotated as $V v T C P 1$ to $V v T C P 18$ on the basis of their distributions in genome and relative linear orders among the respective chromosome.

Protparam tool was used to analyze the physical and chemical characterizations of the VvTCP proteins (Table 1). The length of VvTCP proteins varied from 169 to (VvTCP14) 460 amino acid residues (VvTCP9). VvTCP14 showed the lowest value of the molecular weight $(17.72 \mathrm{kDa})$, while the highest of the molecular weight $(48.54 \mathrm{kDa})$ was observed in VvTCP6. The values of theoretical isoelectric point (pI) ranged from 6.09 to 9.71. The value of the aliphatic index ranged from 56.37 to 80.36 , which suggested that the VvTCP proteins contained rich aliphatic amino acids. The GRAVY of all VvTCP proteins was less than zero, indicating that VvTCPs were hydrophilic. The majority of VvTCP proteins were predicted to be located on the nucleus by WoLF PSORT, but a few of them may be located in other subcellular compartments, such as chloroplast and cytoplasm (Table 1).

\section{Phylogenetic analysis and classification of the VvTCP family}

To explore the evolutionary and phylogenetic relationships between grapevine TCP proteins and other known TCPs, the full length of 115 TCP proteins from grapevine, Arabidopsis, rice, strawberry, tomato and two TCP genes (TB1 and $C Y C$ ) with known function were used to construct a phylogenetic tree using Neiboring-Joining method (Fig. 1). Furthermore, in order to assess a better understanding of phylogenetic relationships of VvTCP members, multiplealignment of the core TCP domain of the all VvTCPs was also performed. Both the phylogenetic analysis and TCP domain alignment suggested that the grapevine TCP proteins were classified into two classes: class I (or PCF) contained 10 genes and class II contained 8 genes (Figs. 1a and 2a). Four-amino-acid fewer in the basic domain of class I than class II proteins was the most striking difference observed between these two classes (Fig. 2a). Additionally, the phylogenetic tree showed that class II could be further divided into two subclades, CYC/TB1 and CIN (Figs. 1a and 2a). Furthermore, all Arabidopsis, rice, strawberry and tomato TCPs existed the same class or clade as previous 
Table 1 TCP gene family in grapevine

\begin{tabular}{|c|c|c|c|c|c|c|c|c|c|c|}
\hline Gene Name & $\begin{array}{l}\text { Accession } \\
\text { number }\end{array}$ & Protein & Chrom & Chr srart & Chr end & $\mathrm{MW}(\mathrm{Da})$ & $\mathrm{pl}$ & $\begin{array}{l}\text { Aliphatic } \\
\text { index }\end{array}$ & GRAVY & LOC \\
\hline$\overline{\text { VvTCP1 }}$ & $\begin{array}{l}\text { VIT_01s0011 } \\
\text { g0292.t01 }\end{array}$ & 438 & Chr1 & $2,574,244$ & $2,575,738$ & $48,349.63$ & 9.43 & 69.04 & -0.562 & $\begin{array}{l}\text { nucl: } 7.5 \text {, golg: } 5 \text {, } \\
\text { cyto_nucl: } 4.5\end{array}$ \\
\hline VvTCP2 & $\begin{array}{l}\text { VIT_01s0026 } \\
\text { g0220.t01 }\end{array}$ & 353 & Chr1 & $11,610,314$ & $11,611,375$ & $38,054.39$ & 8.93 & 62.49 & -0.627 & nucl: 13 \\
\hline VvTCP3 & $\begin{array}{l}\text { VIT_02s0025 } \\
\text { g0459.t01 }\end{array}$ & 411 & Chr2 & $4,140,127$ & $4,141,512$ & $43,499.20$ & 6.20 & 69.59 & -0.296 & nucl: 13 \\
\hline VvTCP4 & $\begin{array}{l}\text { VIT_08s0040 } \\
\text { g0160.t01 }\end{array}$ & 204 & Chr8 & $12,723,686$ & $12,724,300$ & $21,699.26$ & 8.46 & 60.83 & -0.507 & $\begin{array}{l}\text { nucl: } 6, \text { mito: } \\
\text { 6, cyto: } 2\end{array}$ \\
\hline VvTCP5 & $\begin{array}{l}\text { VIT_10s0003 } \\
\text { g0087.t01 }\end{array}$ & 382 & Chr10 & $2,112,286$ & $2,113,434$ & $42,398.40$ & 6.40 & 76.65 & -0.519 & $\begin{array}{l}\text { nucl: } 10, \text { chlo: } \\
\text { 1, cyto: } 1\end{array}$ \\
\hline VvTCP6 & $\begin{array}{l}\text { VIT_10s0003 } \\
\text { g0391.t01 }\end{array}$ & 444 & Chr10 & $6,666,048$ & $6,667,382$ & $48,535.28$ & 7.84 & 58.02 & -0.873 & nucl: 13 \\
\hline VvTCP7 & $\begin{array}{l}\text { VIT_10s0042 } \\
\text { g0017.t01 }\end{array}$ & 255 & Chr10 & $12,942,744$ & $12,943,511$ & $26,159.42$ & 9.71 & 73.29 & -0.234 & $\begin{array}{l}\text { nucl: } 7 \text {, chlo: } \\
3, \text { mito: } 3\end{array}$ \\
\hline VvTCP8 & $\begin{array}{l}\text { VIT_12s0028 } \\
\text { g0252.t01 }\end{array}$ & 307 & Chr12 & $3,281,712$ & $3,282,899$ & $33,699.77$ & 6.41 & 74.04 & -0.386 & nucl: 11 , chlo: 2 \\
\hline VvTCP9 & $\begin{array}{l}\text { VIT_12s0035 } \\
\text { g0069.t01 }\end{array}$ & 460 & Chr12 & $20,150,532$ & $20,151,914$ & $48,077.84$ & 6.57 & 56.37 & -0.668 & nucl: 14 \\
\hline VVTCP10 & $\begin{array}{l}\text { VIT_14s0083 } \\
\text { g0015.t01 }\end{array}$ & 388 & Chr14 & $22,124,744$ & $22,125,983$ & $44,040.07$ & 9.57 & 68.43 & -0.672 & $\begin{array}{l}\text { nucl: } 10.5 \text {, cyto } \\
\text { nucl: } 6.5 \text {, chlo: } \overline{2}\end{array}$ \\
\hline VVTCP11 & $\begin{array}{l}\text { VIT_14s0068 } \\
\text { g0033.t01 }\end{array}$ & 349 & Chr14 & $24,046,932$ & $24,047,981$ & $38,623.45$ & 8.79 & 76.50 & -0.573 & $\begin{array}{l}\text { nucl: } 10.5 \text {, nucl_ } \\
\text { plas: } 6 \text {, chlo: } 1\end{array}$ \\
\hline VvTCP12 & $\begin{array}{l}\text { VIT_14s0068 } \\
\text { g0169.t01 }\end{array}$ & 296 & Chr14 & $25,396,768$ & $25,397,658$ & $31,511.13$ & 9.01 & 68.95 & -0.625 & nucl: 12, chlo: 1 \\
\hline VvTCP13 & $\begin{array}{l}\text { VIT_15s0048 } \\
\text { g0115.t01 }\end{array}$ & 339 & Chr15 & $15,268,480$ & $15,269,562$ & $36,052.01$ & 8.96 & 72.92 & -0.343 & nucl: 11, cyto: 2 \\
\hline VVTCP14 & $\begin{array}{l}\text { VIT_16s0022 } \\
\text { g0248.t01 }\end{array}$ & 169 & Chr16 & $15,211,547$ & $15,212,056$ & $17,721.95$ & 6.62 & 80.36 & -0.307 & nucl: 10 , cyto: 3 \\
\hline VVTCP15 & $\begin{array}{l}\text { VIT_17s0000 } \\
\text { g0418.t01 }\end{array}$ & 366 & Chr17 & $4,344,260$ & $4,345,620$ & $41,570.75$ & 8.88 & 66.69 & -0.757 & $\begin{array}{l}\text { nucl: } 8 \text {, cyto: } 3 \text {, } \\
\text { chlo: } 1\end{array}$ \\
\hline VVTCP16 & $\begin{array}{l}\text { VIT_17s0000 } \\
\text { g0602.t01 }\end{array}$ & 369 & Chr17 & $6,588,791$ & $6,589,900$ & $39,568.76$ & 7.20 & 58.73 & -0.640 & nucl: 14 \\
\hline VvTCP17 & $\begin{array}{l}\text { VIT_18s0117 } \\
\text { g0030.t01 }\end{array}$ & 355 & Chr18 & $23,608,849$ & $23,609,916$ & $37,106.80$ & 6.09 & 60.82 & -0.555 & nucl: 14 \\
\hline VVTCP18 & $\begin{array}{l}\text { VIT_19s0014 } \\
\text { g0168.t01 }\end{array}$ & 398 & Chr19 & $1,805,797$ & $1,806,993$ & $43,306.70$ & 6.27 & 58.19 & -0.695 & nucl: 14 \\
\hline
\end{tabular}

AA amino acid residues, Chrom chromosome, MW molecular weight, $p /$ theoretical isoelectric point, GRAVY grand average of hydropathicity, Loc subcellular location. The subcellular location results of grapevine BBX genes were predicted by WoLF PSORT (https://www.genscript.com/wolf-psort.html). Nucl nucleus, Chlo chloroplast, Cyto cytosol, Mito mitochondria. Testk used for kNN is: 14

reports [21, 31, 54], confirming the reliability of our phylogenetic tree. According to the classification, the CYC/ TB1 subclade contained $3 V v T C P$ genes ( $V v T C P 1$, $V v T C P 10$ and $V v T C P 15)$ and the CIN subclade included 5 $V v T C P$ genes $(V v T C P 5, V v T C P 6, V v T C P 8, V v T C P 11$ and VvTCP18).

Expect for the TCP domain, several class II TCP members also share an $\mathrm{R}$ domain, which is an approximately 18-residues arginine-rich motif. As shown in Fig. 2b, four class II proteins, VvTCP1, VvTCP10 and VvTCP15 from grapevine class II CYC/TB1 as well as VvTCP6 from $\mathrm{CIN}$, contained the $\mathrm{R}$ domain at the $\mathrm{C}$-terminus of the TCP domain. The VvTCP6 in the CIN subclade was less conserved than CYC/TB1 subclade, in agreement with the previous in tomato and Phalaenopsis equestris $[21,55]$. Additionally, three CIN subclade genes ( $V v T C P 5, V v T C P 6$ and $V v T C P 18)$ included the potential miR319 target site and displayed high sequence homology with the Arabidopsis and tomato miR319-targeted TCP genes (Figs. 1a and 2c).

\section{Gene structure analysis and conserved motif identification}

To further understand into the evolutionary relationships and structural features of the TCP protein in grapevine, the exon/intron structures and conserved 


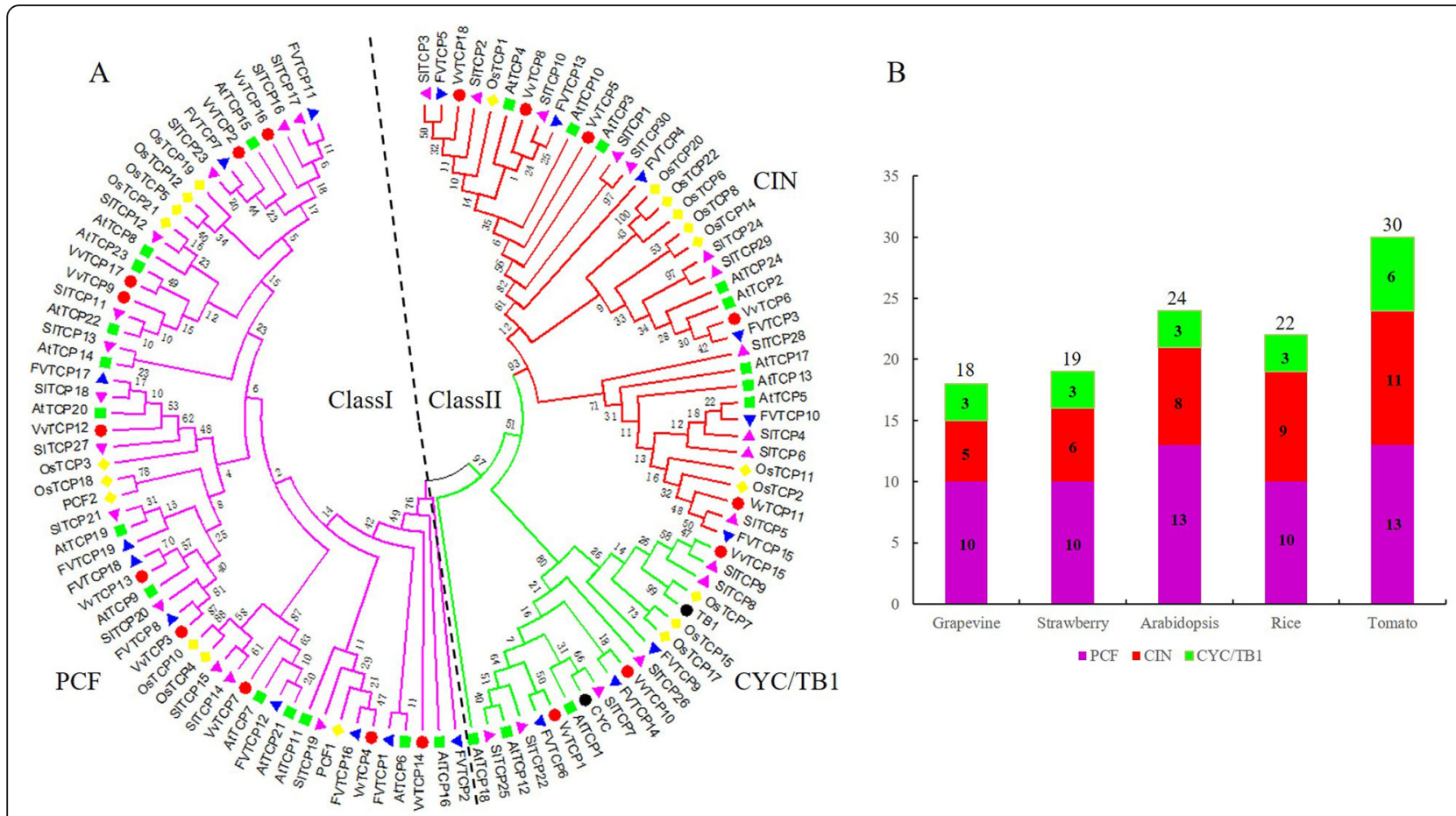

Fig. 1 Phylogenetic analysis of TCP family among grapevine, strawberry, Arabidopsis, rice and tomato. a The full-length amino acid sequences of TCP from grapevine (VvTCP), strawberry (FVTCP), Arabidopsis (AtTCP), rice (OsTCP), tomato (SITCP), the Antirrhinum CYC and maize TB1 were aligned by ClustalX, and the phylogenetic tree was constructed using the neighbor-joining method with 1000 bootstrap replicates by MEGA7.0. The branched lines of the subtrees are colored to indicate different TCP subgroups. b TCP family members of grapevine, strawberry, Arabidopsis, rice and tomato

motifs of VvTCPs were investigated. The conserved TCP domain sequences of VvTCP protein were used to construct a new phylogenetic tree, which also divided the VvTCP proteins into three subgroups (Fig. 3a). As shown in Fig. 3b, almost all $V v T C P$ genes exhibited highly conserved exon-intron organization: 12 out of 18 $V v T C P$ genes were no intron, four $V v T C P$ genes had one intron, and two $V v T C P$ genes had two introns. As expected, most of $V v T C P$ genes within same subfamily exhibited similar distribution patterns of exon/intron in terms of exon length and intron number, which supported the classification of subclade and evolutionary relationship (Fig. 3b).

To get more insight into the diversity of motif compositions among VvTCPs, five conserved motifs were identified by MEME program. The results showed that the highly conserved TCP domain (motif 1 ) was existed in all VvTCP proteins (Fig. 3c and Additional file 1: Figure S2). The conserved $\mathrm{R}$ domain (motif 3 ) was hit in four class II VvTCP proteins. All class I members were characterized by motif 2 in C-terminal TCP domain. By comparison, the $\mathrm{N}$-terminal TCP domain of motif 4 was detected in all class II proteins. Additionally, motif 5 were exclusively present in PCF, which was consistent with the previous report that some motifs existing in a particular subgroup may contribute to the specific function of those genes in the subgroup [31, 56]. Togerher, VvTCP proteins clustered in same subgroup demonstrated similar motif composition, which was in agreement with the gene structure analysis.

\section{Tandem duplication and synteny analysis of VvTCP genes}

To reveal the mechanism for expansion and evolution of the $V v T C P$ gene family, potential gene duplication events were investigated in the of grapevine genome. As illustrated in Fig. 4 and Additional file 3: Table S2, eight pairs of paralogous $V v T C P$ genes were identified and distributed on different chromosomes in grapevine, whereas no tandem duplication events were observed, suggesting that segmental duplications were the main causes for the amplification of $V v T C P$ gene family. In addition, six genes involved in two segmental duplication events (VvTCP1/ $V v T C P 10 / V v T C P 15$ and $V v T C P 5 / V v T C P 8 / V v T C P 18)$.

Furthermore, a large-scale comparative synteny maps between grapevine and Arabidopsis, grapevine and tomato was analyzed at genome-wide levels with purpose to clarify the origin and function of TCP genes. A total of eight pairs of TCP genes were identified between grapevine and Arabidopsis (Additional file 1: Figure S3 and Additional file 3: Table S2), while 37 pairs of TCP 


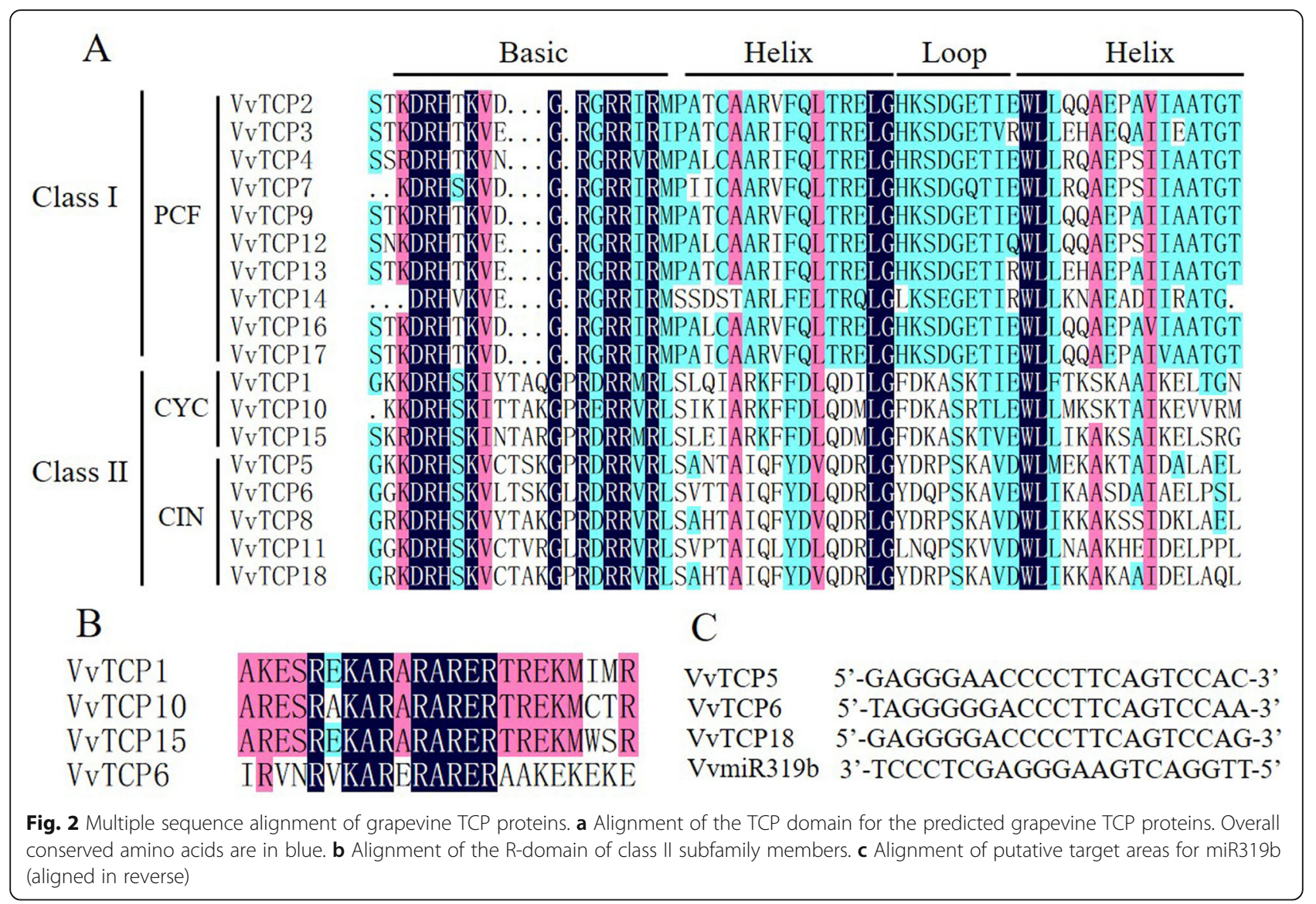

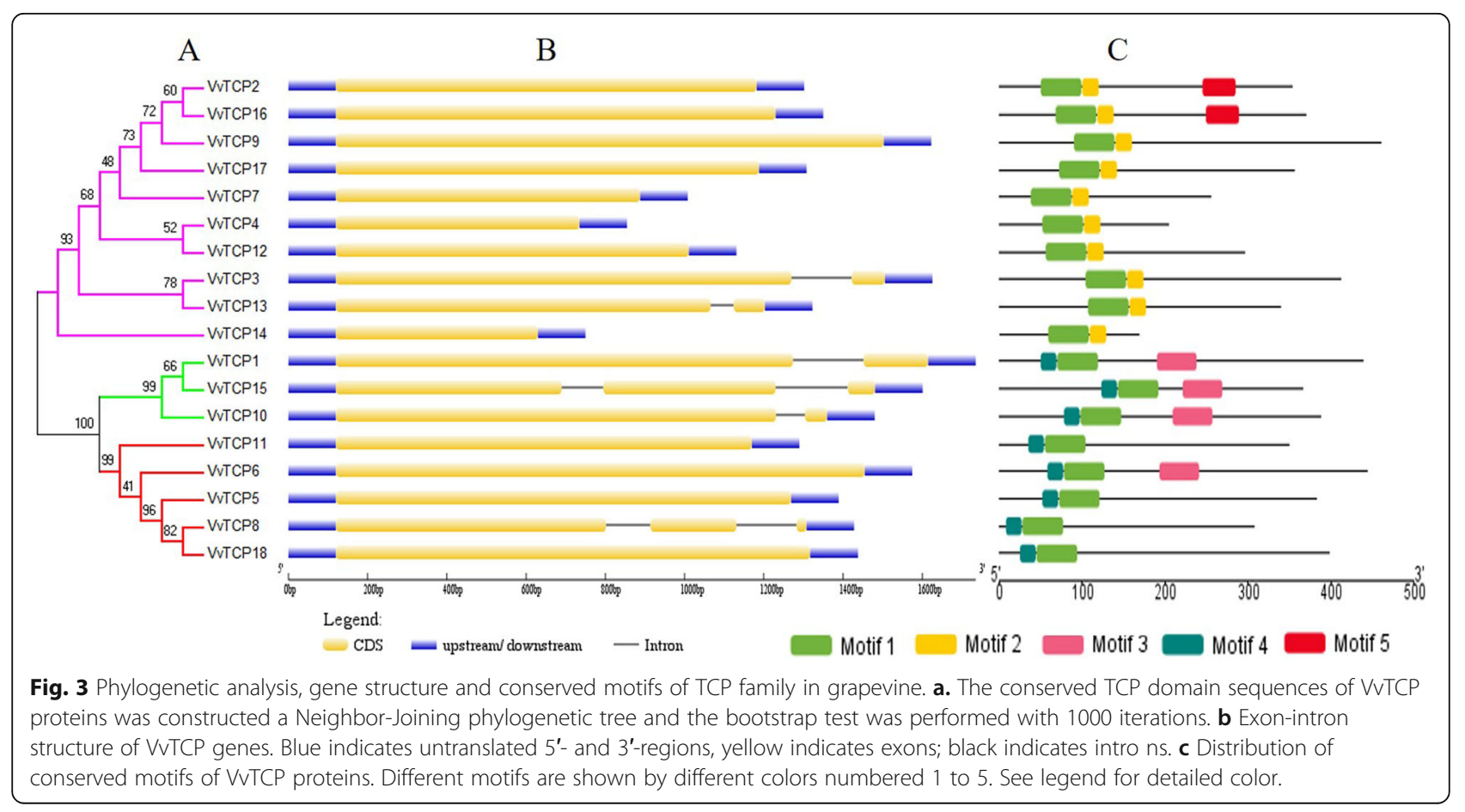




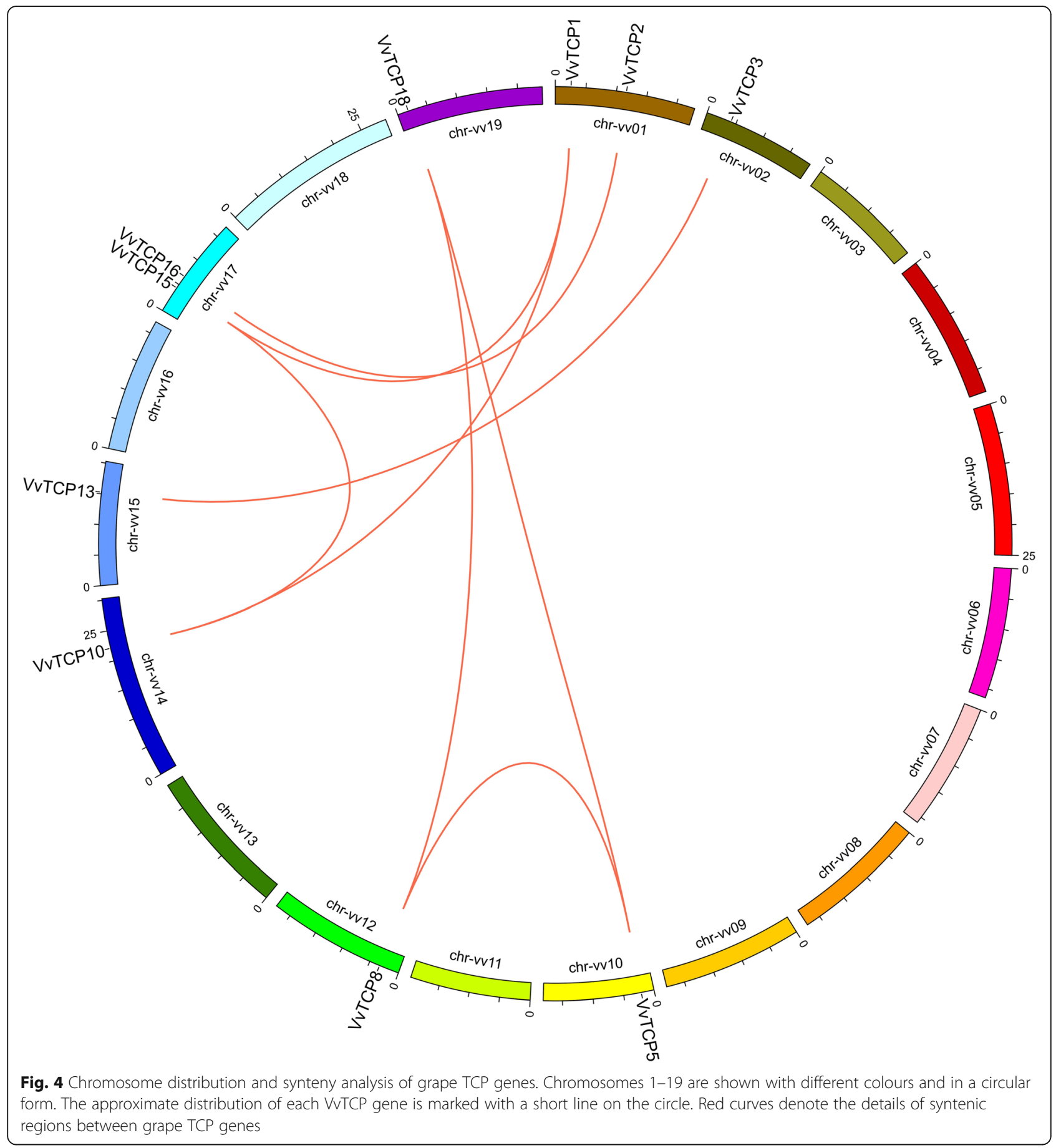

genes, including $12 V v T C P$ genes and 17 SlTCP genes, showed syntenic relationship (Additional file 1: Figure S4 and Additional file 1: Table S2), suggesting that most TCPs had orthologous in Arabidopsis and tomato. Among the synteny events between grapevine and tomato, 8 $V v T C P$ genes were found to be associated with at least three synteny events, such as VvTCP5- SlTCP1/SlTCP2/SlTCP3/ SlTCP10/SlTCP30 and VvTCP15-SlTCP7/SlTCP8/SlTCP9/ SlTCP22/SlTCP25 (Additional file 3: Table S2). Interestingly, six out of these eight genes were in CIN and CYC/TB1 subclade, indicating a higher conservation of CIN and CYC/TB1 than PIF subclade in TCP gene family.

\section{Promoter Cis-regulatory elements analysis of grapevine} VvTCP genes

To further insight into the gene function and regulation mechanism of $V v T C P$ genes, the cis-regulatory elements in promoter sequences were analyzed. The 
promoter regions (1, $500 \mathrm{bp}$ of genomic DNA sequence upstream of the translation starts site) of the VvTCP genes were submitted in PlantCARE database. In addition to the basic TATA and CAAT boxes, a large number of cis-acting elements involved in phytohormone responses, plant growth and development and stress responses were identified (Fig. 5; Additional file 4: Table S3). As show in Fig. 5, two cis-acting regulatory elements involved in endosperm expression (GCN4_motif and Skn-1_motif) were identified in promoter region of 6 and $17 V v T C P$ genes, respectively. Three cis-acting regulatory elements were related to meristem expression (CAT-box, CCGTCCbox and dOCT) in plant growth and development. The shoot-specific expression element (as-2-box) and circadian control element (circadian) were found in 7 and $8 V v T C P$ genes, respectively. Additionally, the flavonoid biosynthetic (MBSI), zein metabolism regulation element (O2 site) and root specific (motif I) regulatory element were also found in the promoter region of the $V v T C P$ genes (Fig. 5; Additional file 4: Table S3).

In hormone-related cis-acting elements, the ABAresponsive element (ABRE), the salicylic acid (SARE and TCA-element), the MeJA-responsive element (CGTCAmotif and TGACG-motif) and the gibberellin-responsive element (P-box, GARE-motif and TATC-box) were identified in the promoter region of 13,14, 10 and $13 V v T C P$ genes, respectively (Fig. 5; Additional file 4: Table S3).
Ethylene-responsive element (ERE) and auxin-responsive element (AuxRR-core and TGA-element were observed in 5 and $6 V v T C P$ genes respectively (Fig. 5; Additional file 4: Table S3). Plenty of hormone-responsive elements were observed in the promoter region of $V v T C P$ genes, revealing that hormones could play important functions in the regulation of plant growth and development (Fig. 5). In stress-related cis-acting elements, anaerobic induction (ARE), drought-inducibility (MBS), heat stress (HSE) and low-temperature (LTR) responsiveness element were also detected in the promoters of 14, 15, 12 and $6 \mathrm{VvTCP}$ genes, respectively (Fig. 5; Additional file 4: Table S3).

\section{Tissue-specific expression patterns of VvTCP genes in grapevine}

To gain more insights in potential roles of $V v T C P$ genes during grapevine development, the organicspecific expression patterns of all the $V v T C P$ genes were analysed using an expression atlas of $V$. vinifera cv. 'Corvina' from the GEO DataSets (GSE36128), which contained 42 various organs/tissues at different developmental stages obtained by microarray analysis [45]. Hierarchical clustering was used to present the relative expression levels of $V v T C P$ genes in different tissues. As showed in Fig. 6, some $V v T C P$ genes shared similar expression profiles in various tissues, while other $V v T C P$ genes presented significant tissuespecific expression patterns, possibley suggesting the functional divergence of $V v T C P$ genes in grapevine

\begin{tabular}{|c|c|c|c|c|c|c|c|c|c|c|c|c|c|c|c|c|c|c|c|c|c|c|c|c|c|c|c|c|}
\hline & \multicolumn{10}{|c|}{ Plant growth and development } & \multicolumn{11}{|c|}{ Phytohormone responsive } & \multicolumn{7}{|c|}{ Abiotic and biotic stress } \\
\hline & 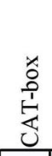 & $\begin{array}{l}0 \\
\text { Oे } \\
0 \\
0 \\
0 \\
0\end{array}$ & 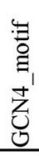 & $\overrightarrow{\tilde{n}}$ & 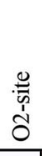 & 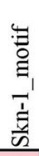 & 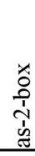 & $\overline{\tilde{z}}$ & $\begin{array}{l}\tilde{Z} \\
0\end{array}$ & 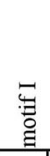 & 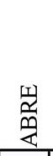 & 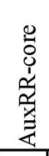 & 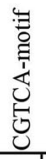 & $\begin{array}{l}\frac{1}{2} \\
\frac{1}{1}\end{array}$ & 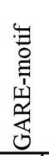 & مئم & 产 & 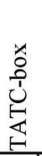 & 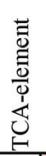 & 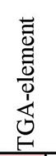 & 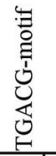 & 琶 & $\begin{array}{l}5 \\
\dot{\hat{i}} \\
\stackrel{0}{0}\end{array}$ & $\begin{array}{l}\text { 诊 } \\
\text {. }\end{array}$ & 萏 & $\sum_{\sum}^{\infty}$ & 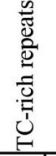 & 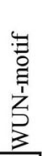 \\
\hline VvTCP1 & \begin{tabular}{|l|}
1 \\
\end{tabular} & 1 & & & 1 & 3 & & & & _ & \begin{tabular}{|l|l|}
1 \\
\end{tabular} & & & & - & - & & L & 1 & 3 & _ & E & - & 1 & 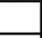 & \begin{tabular}{|l|l|}
3 & $r$ \\
\end{tabular} & & \\
\hline VvTCP2 & & & 1 & & 1 & 2 & & & & & 1 & 1 & & & & & & & 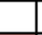 & 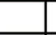 & 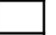 & 1 & & 1 & & & 1 & \\
\hline VvTCP3 & 1 & & 2 & & & 2 & & 1 & & 1 & 6 & & & & 3 & 1 & & 1 & 5 & 1 & & 4 & & & 1 & \begin{tabular}{|l|ll}
1 & \\
\end{tabular} & 2 & \\
\hline VvTCP4 & & & 1 & & & 7 & & & & - & & & 2 & 1 & 1 & 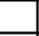 & & & 1 & & 2 & & 3 & & 1 & \begin{tabular}{|l|ll}
2 & \\
\end{tabular} & 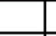 & \\
\hline VvTCP5 & \begin{tabular}{|l|l|}
1 \\
\end{tabular} & & & & & 1 & 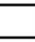 & 3 & & - & \begin{tabular}{|l|l|}
1 \\
\end{tabular} & & 1 & & 2 & 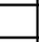 & & 1 & 1 & 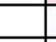 & 1 & 1 & \begin{tabular}{|l|l|}
2 \\
\end{tabular} & & & \begin{tabular}{|l|l|}
2 \\
\end{tabular} & & \\
\hline VvTCP6 & & & & 1 & & 4 & & & 1 & 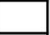 & & & 1 & 1 & 2 & & & & 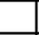 & & 1 & 3 & & 3 & 2 & 1 & 1 & \\
\hline VvTCP7 & 1 & & & & 1 & 1 & 1 & 1 & & Z & 2 & & 1 & 1 & & 1 & & & - & 1 & 1 & 1 & & 5 & 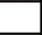 & 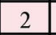 & 2 & 1 \\
\hline VvTCP8 & & & 1 & & & & 1 & & & & 1 & & & & & 1 & & & 2 & & & \begin{tabular}{|l|l|}
2 \\
\end{tabular} & & 1 & & \begin{tabular}{|l|l}
2 \\
\end{tabular} & 1 & \\
\hline VvTCP9 & & & & & & 3 & & & & 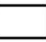 & & & 2 & & & 1 & & & 2 & & 2 & \begin{tabular}{|l|}
1 \\
\end{tabular} & \begin{tabular}{|l|l|}
1 & \\
\end{tabular} & 1 & & \begin{tabular}{|l|l|}
1 & \\
\end{tabular} & 1 & \\
\hline VvTCP10 & 1 & & & & & 3 & & & & - & 1 & & 1 & & 1 & & & & 2 & & 1 & 4 & \begin{tabular}{|l|} 
\\
\end{tabular} & & & \begin{tabular}{|l|}
1 \\
\end{tabular} & & \\
\hline VvTCP11 & & 1 & & & 2 & 3 & 1 & 2 & & 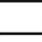 & 2 & & 1 & & & 1 & & & 3 & & 1 & 1 & 1 & 1 & & 3 & 2 & \\
\hline VvTCP12 & 3 & & & & & 3 & 1 & & & 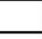 & \begin{tabular}{|l|}
2 \\
\end{tabular} & & & & 1 & & & & 1 & & & \begin{tabular}{|l|}
2 \\
\end{tabular} & & 4 & & \begin{tabular}{|l|}
2 \\
\end{tabular} & 2 & 1 \\
\hline VvTCP13 & & & & & & 1 & & & & 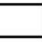 & 1 & & & 1 & 4 & & & & 3 & & & - & \begin{tabular}{|l|}
1 \\
\end{tabular} & & 1 & \begin{tabular}{|l|}
3 \\
\end{tabular} & 1 & \\
\hline VvTCP14 & & & & & & 3 & 1 & 1 & & 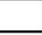 & \begin{tabular}{|l|}
1 \\
\end{tabular} & & & & & & & & 1 & & & \begin{tabular}{|l|}
5 \\
\end{tabular} & & 1 & & 1 & & \\
\hline VvTCP15 & 1 & & & & & 2 & & & & & 3 & & 1 & 1 & & & & & 4 & & 1 & \begin{tabular}{|l|}
2 \\
\end{tabular} & & 1 & & & & \\
\hline VvTCP16 & 1 & & & & & 1 & & 1 & & 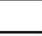 & \begin{tabular}{|l|}
3 \\
\end{tabular} & & & & & 2 & & & & 1 & & & & - & 1 & \begin{tabular}{|l|}
1 \\
\end{tabular} & & \\
\hline VvTCP17 & & & 1 & & 1 & 5 & 2 & 3 & & 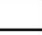 & & & 2 & & & & 1 & & 3 & 1 & 2 & \begin{tabular}{|l|}
1 \\
\end{tabular} & & 1 & & & 1 & \\
\hline VvTCP18 & 2 & & 1 & & 1 & 3 & 1 & 3 & & & & & 4 & & & 2 & & & 3 & & 4 & 3 & & 1 & & \begin{tabular}{|l|}
4 \\
\end{tabular} & \begin{tabular}{l|l} 
\\
\end{tabular} & \\
\hline
\end{tabular}

Fig. 5 Promoter Cis-regulatory elements analysis of grapevine VVTCP genes. Number of each cis-acting element in the promoter region (1.5 kb upstream of the translation start site) of $V_{V T C P}$ genes. Based on the functional annotation, the cis-acting elements were classified into three major classes: plant growth and development, phytohormone responsive, or abiotic and biotic stresses-related cis-acting elements (detailed results shown in Supplementary Table S2) 


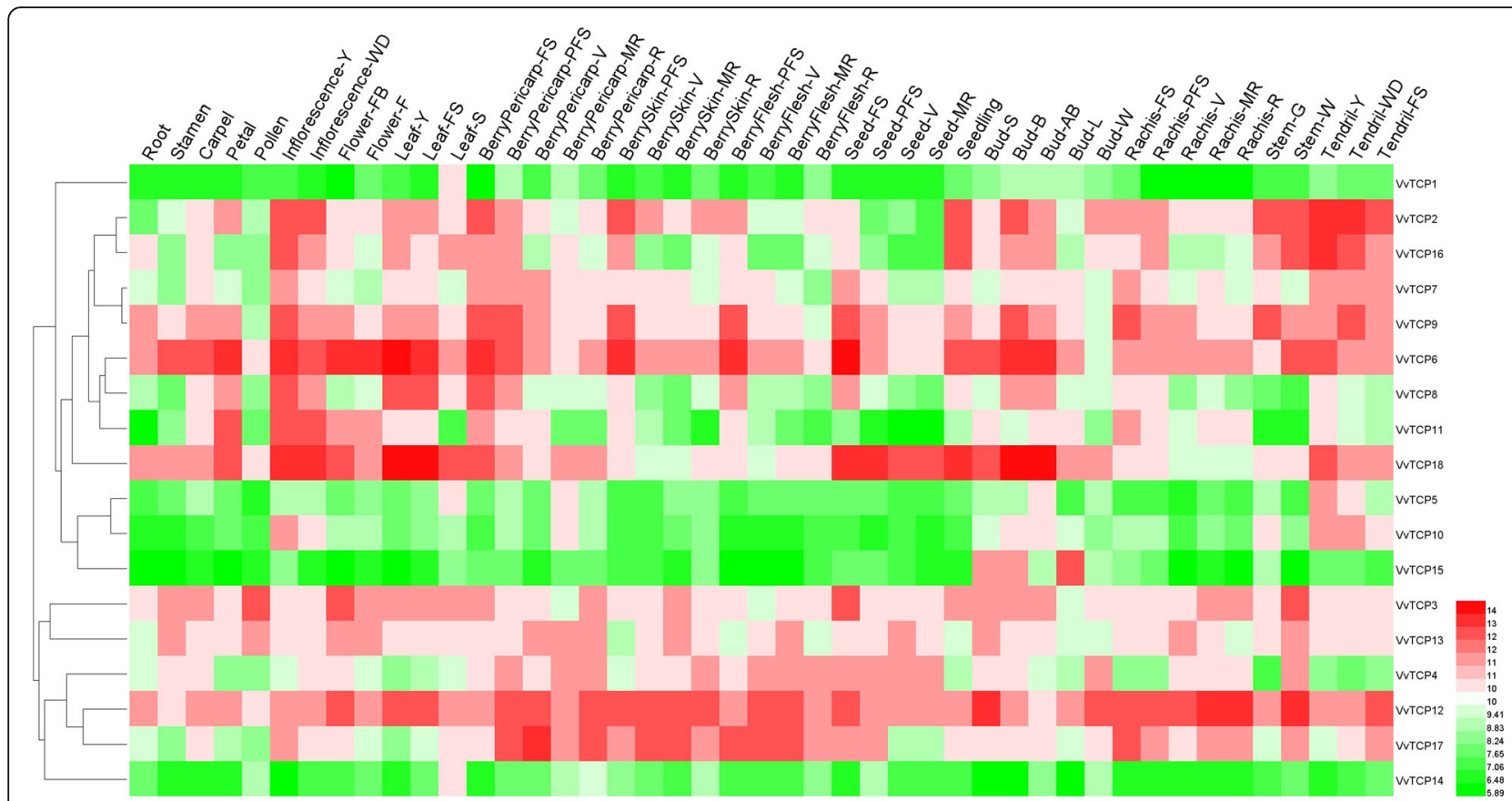

Fig. 6 Expression profiles of grapevine VVTCP genes in various tissues and developmental stages. Expression data were normalized based on the mean expression value of each gene in all tissues analysed. Genes were hierarchically clustered based on average Pearson's distance metric and 'average linkage' method. Red and green boxes indicate high and low expression levels, respectively, for each gene. Bud-AB, bud after burst; BudB, Bud burst; Bud-W, winter bud; Bud-L, latent bud; Bud-S, bud swell; Flower-F, flowering; Flower-FB, flowering begins; FS, fruit set; Inflorescence-Y, young inflorescence with single flowers separated; Inflorescence-WD, well-developed inflorescence; Leaf-FS, mature leaf; Leaf-S, senescing leaf; Leaf-Y, young leaf; MR, mid-ripening; R, ripening; PFS, post fruit set; Stem-G, green stem; Stem-W, woody stem; V, véraison

organs/tissues during development. For example, $V v T C P 6$ and $V v T C P 12$ were constitutively high expressed in almost all tested issue, whereas $V v T C P 1$, $V v T C P 5, V v T C P 10$ and $V v T C P 14$ were expressed at extreme low levels in all tissues (Fig. 6, Additional file 5: Table S4).

In contrast, the expression levels of $V v T C P 2$ and $V v T C P 16$ were very high in young inflorescence, seedling and woody stem and they were relatively low expression in seed and pollen, implying that they might be involved in the development of inflorescence, seedling and woody stem (Fig. 6, Additional file 5: Table S4). $V v T C P 15$ was only high relative expression level in latent bud, bud swell or bud burst and at almost undetectable levels in other tissues, suggesting that $V v T C P 15$ might plant an important role in the development of grapevine buds (Fig. 6, Additional file 5: Table S4). $V v T C P 11$ displayed high expression in petal, young inflorescence or well-developed inflorescence, indicating an involvement in flower development. Additionally, $V v T C P 8$ showed relatively high expression in young leaves and inflorescence, $V v T C P 18$ was extremely high transcript levels in young leaves, mature leaves, burst bud and bud after burst. Remarkably, some $V v T C P$ genes $(V v T C P 2,3,6,8,9$ and 11$)$ were gradually decreased expression patterns from the green fruit stage to the veraison/ripe stage (Fig. 6, Additional file 5: Table S4), which indicated that these genes might play important roles in fruit development. These results prompted us to investigate the transcript accumulation patterns of $V v T C P$ genes during grapevine fruit development and ripening.

\section{Expression patterns of $V v T C P$ genes during different berry developmental stages}

To understand the potential function of $V v T C P$ genes in berry development and ripening, the transcript accumulation patterns of $18 V v T C P$ genes were investigated during three fruit developmental stages in grapevine using the expression profiles from the GEO DataSets (GSE77218) [47]. As shown in Fig. 7a, five $V v T C P$ genes (VvTCP1 , 5, 10, 14 and 15) were almost undetectable during the whole processes of berry development in grapevine (Fig. 7a, Additional file 6: Table S5). Eleven VvTCP genes ( $V v T C P 2,3,4,6,7,8,9,11,12,16$ and 18) displayed the highest expression levels at green fruit stage, and then showed decreasing trend from veraison till to ripe stage, indicating potential roles during early berry development. On the contrary, the expression of $V v T C P 13$ was increased gradually during three berry development stages. 


\begin{tabular}{|c|c|c|c|}
\hline $\begin{array}{r}\text { A } \\
\text { \#Gene }\end{array}$ & (5) & $\Delta^{0}$ & يे \\
\hline \multicolumn{4}{|l|}{ VvTCP1 } \\
\hline VvTCP2 & 10.6 & & \\
\hline VvTCP3 & 6.8 & & \\
\hline VvTCP4 & 17.1 & 11.6 & 13.6 \\
\hline \multicolumn{4}{|l|}{ VvTCP5 } \\
\hline VvTCP6 & 7.1 & & \\
\hline VvTCP7 & 83.0 & 44.9 & 41.2 \\
\hline \multicolumn{4}{|l|}{ VvTCP8 } \\
\hline VvTCP9 & 5.4 & & \\
\hline \multicolumn{4}{|l|}{ VvTCP10 } \\
\hline VvTCP11 & 9.9 & & \\
\hline VvTCP12 & 33.8 & 22.3 & 11.0 \\
\hline VvTCP13 & 5.8 & 6.5 & 16.0 \\
\hline \multicolumn{4}{|l|}{ VvTCP14 } \\
\hline \multicolumn{4}{|l|}{ VvTCP15 } \\
\hline VvTCP16 & - & & \\
\hline VvTCP17 & 41.2 & 51.2 & 26.5 \\
\hline VvTCP18 & 5.2 & & \\
\hline
\end{tabular}

\section{$\mathrm{B}$}
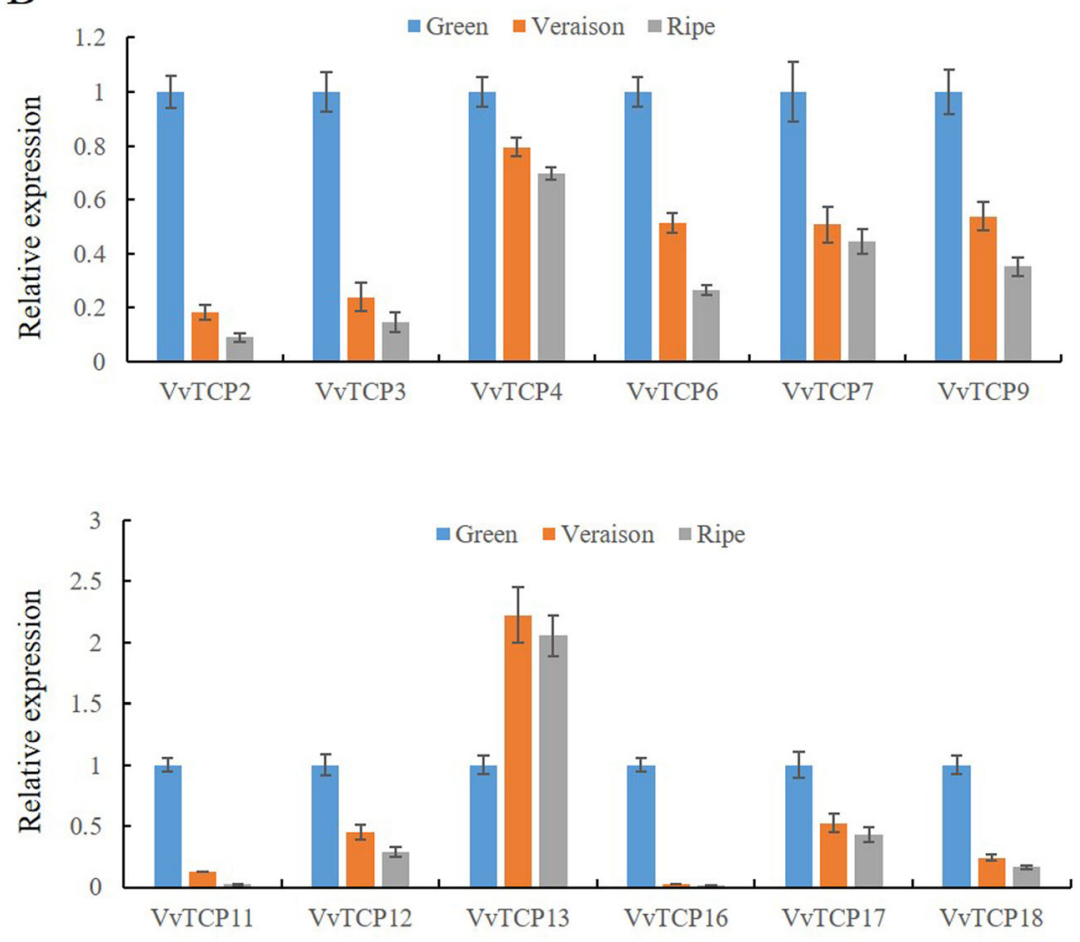

Fig. 7 Expression profile of grapevine VVTCP genes during three fruit developmental stages. a Hierarchical clustering of the transcript accumulation profiles of 18 VvTCP genes during three berry developmental stages. $\mathbf{b}$ RT-qPCR transcript analysis of 12 selected VvTCP genes at three berry developmental stages. Berries from 3 year old 'Fujiminori' grapevine trees were sampled in triplicate at the fruit expanding (40DAF or DAF40), veraison (65DAF or DAF65), and ripe (90DAF or DAF90) stages throughout the growing season. The experiments were repeated three times and provided consistent results

In order to validate the expression pattern of $V v T C P$ genes in the various developmental stages of the berry by microarray data, qRT-PCR analysis of 12 detectable $V v T C P$ genes was further performed at three berry development stages. As was expected, qRT-PCR results were highly consistent with the RNA-Seq data except for $V v T C P 17$ (Fig. 7b). For example, $V v T C P 2, V v T C P 3$ and $V v T C P 7$ showed a relatively high expression levels in green stage but decreased sharply in veraison stage, and then changed slightly from veraison to ripening stage (Fig. 7b). VvTCP13 was significantly higher expression in at ripe stage than that in green stage. However, the expression profiles of $V v T C P 17$ did not correspond with RNA-Seq data. $V v T C P 17$ was relatively high expression in veraison berry from RNA-Seq data, whereas the qRT-PCR analysis showed the highest expression in green berry stage (Fig. 7b). All these results implied that $V v T C P$ genes might be involved in grapevine fruit development.

To provide more information on the berry developmental and ripening functions of $V v T C P$ genes in grapevine, we investigated their transcript accumulation patterns among 10 different grapevine varieties by using microarray data (accession numbers GSE62744 and GSE62745), which consists of four different fruit developmental stages (the pea-sized berry stage at 20d after flowering, the berries beginning to touch stage just prior to veraison, the berry-softening stage at the end of veraison, and the fully ripe berry stage at harvest [48]. As shown in Fig. 8, four detected $V v T C P$ genes ( $V v T C P 6,7$, 9 and 11) were relatively higher expression in pea-sized berry and Pre_veraison stage and rapidly down-regulated during ripening, which were corresponded with the data from RNA-Seq and qRT-PCR analysis. Interestedly, $V v T C P 6$ were intensely expressed in pea-sized berry, implying that VvTCP6 may play an important role during the early stages of grapevine berry development. Additionally, $V v T C P 13$ was only detected at ripe stage (Fig. 8), which indicated that $V v T C P 13$ might function in grapevine fruit ripening. All these results indicated that some $V v T C P$ genes might play important roles in grapevine fruit development.

Transcript profiling of $V v T C P$ genes under various abiotic stress treatments

Copper $(\mathrm{Cu})$, salt, waterlogging and drought are common types of abiotic stresses in vineyards. To investigate the potential roles of the $V v T C P$ genes in responses to 


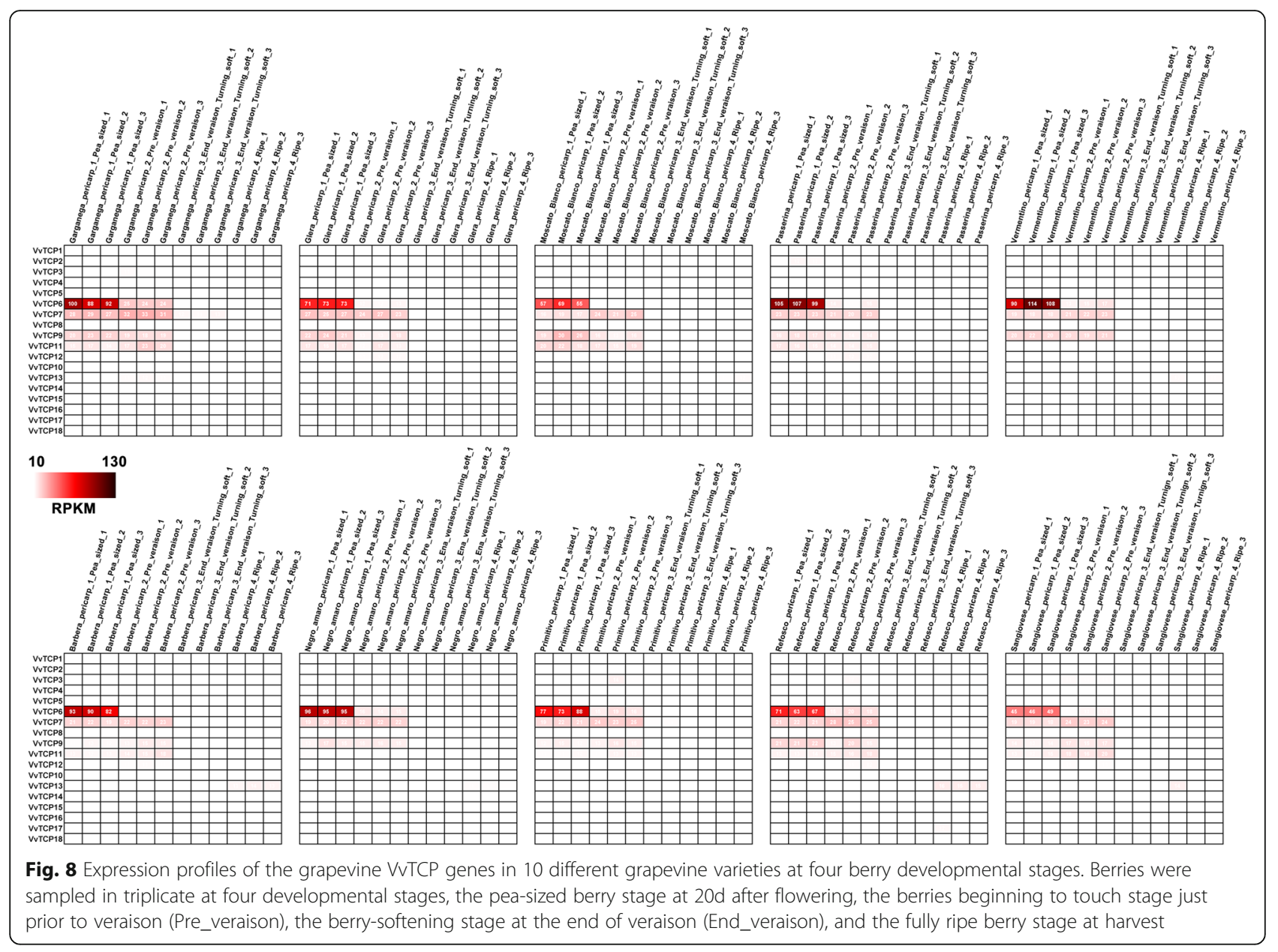

different environmental stresses, the RNA-seq datas were collected for the $18 V v T C P$ genes in the leaves of the grapevine exposed to $\mathrm{Cu}, \mathrm{NaCl}$, waterlogging and drought treatment (Fig. 9, Additional file 7: Table S6). Overall, the $V v T C P$ genes responded to waterlogging and drought stress to a greater extent than to $\mathrm{Cu}$ and $\mathrm{NaCl}$ treatment. For example, eight $V v T C P$ genes were regulated in response to waterlogging treatment and seven $V v T C P$ genes responded to drought stress (Fig. 9, Additional file 7: Table S6). In contrast, only three (VvTCP8, 9 and 13) and one (VvTCP3) VvTCP genes were down-regulated expression in response to $\mathrm{Cu}$ and salinity stress, respectively, while the other $V v T C P$ members were only slightly down-regulated or remained nearly unchanged (Fig. 9, Additional file 7: Table S6). Notably, three $V v T C P$ genes $(V v T C P 8,9$ and 13) responded to at least three treatments, indicating that these genes might be involved in multiple stress response processes. Moreover, the expression difference of $V v T C P$ depended on the type of stress. VvTCP13 was up-regulated in response to waterlogging stress, but was down-regulated in response to $\mathrm{Cu}$ and drought stress.

\section{Subcellular localization of VvTCP proteins}

It is well know that the nuclear localization of transcription factors is very important for regulate the transcription of target genes by binding to specific ciselements in their promoters. Previous studies have showed that TCP proteins were predominantly located in the nucleus, such as FvTCP8, FvTCP9 and FvTCP13 in strawberry. In this study, the majority of VvTCP proteins were predicted to be located on the nucleus by WoLF PSORT (Table 1). To characterize the subcellular localization of the VvTCP, three cloned VvTCP genes (VvTCP2-GFP, VvTCP3-GFP and VvTCP18-GFP) were introduced into the pCAMBIA1300 vector by CaMV $35 \mathrm{~S}$ promoter. The recombinant three fusion constructs was infiltrated into N. tabacum epidermal cells. As indicated in Fig. 10, green fluorescence signals from the expressed fusion VvTCP2-GFP, VvTCP3-GFP and VvTCP18-GFP were specifically distributed within the nuclei as confirmed by a mCherry-labelled nuclear marker (NF-YA4mCherry). These results showed that VvTCP2, VvTCP3 and VvTCP18 were nuclear proteins, and 


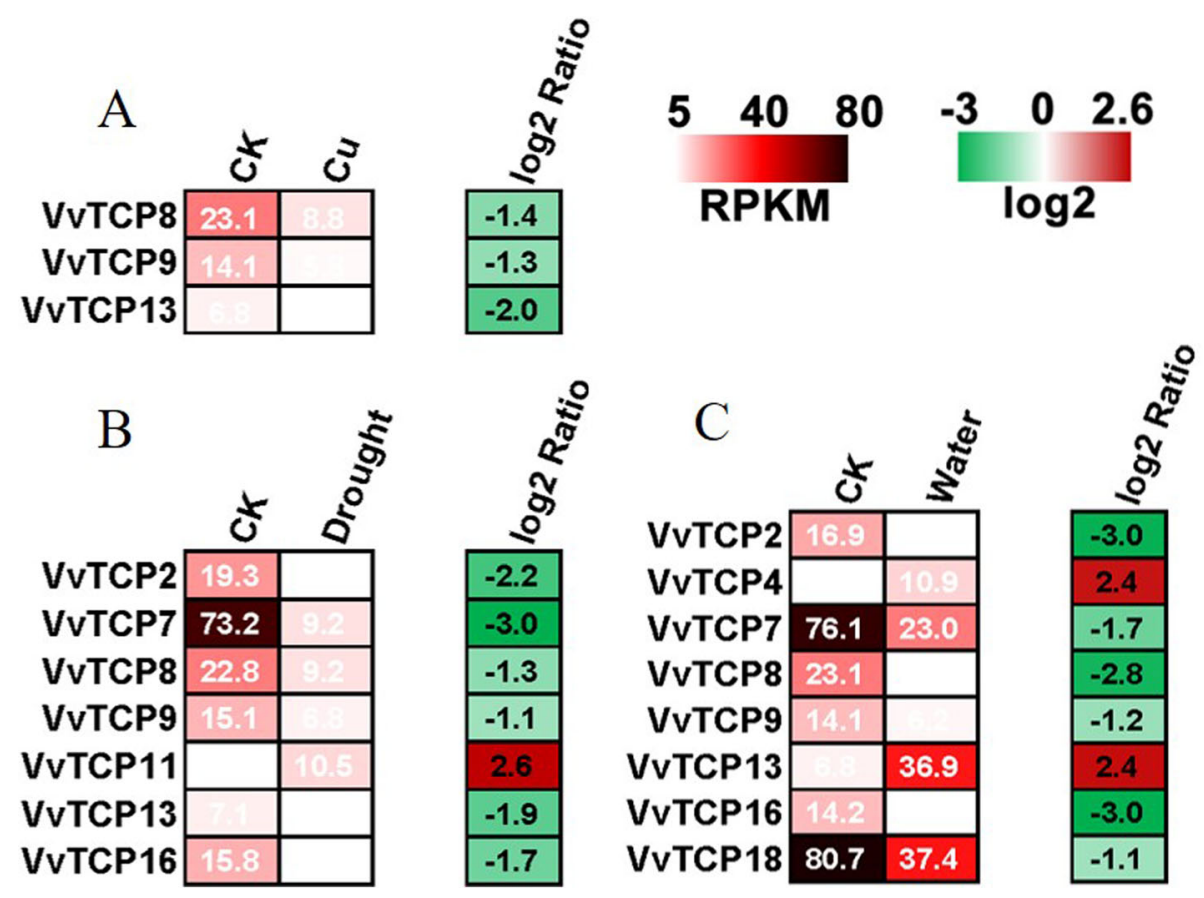

Fig. 9 The expression of VVTCP genes under different abiotic stresses. a-c, Hierarchical cluster displaying the differentially expressed VVTCP genes under $\mathrm{Cu}$, drought and waterlogging treatments. Data were obtained by RNA Sequencing and were expressed as Reads Per Kilobase of exon model per Million mapped reads (RPKM). The differentially expressed data were log2 transformed with R software. Blocks with green colors indicate decreased and red ones indicate increased transcription levels

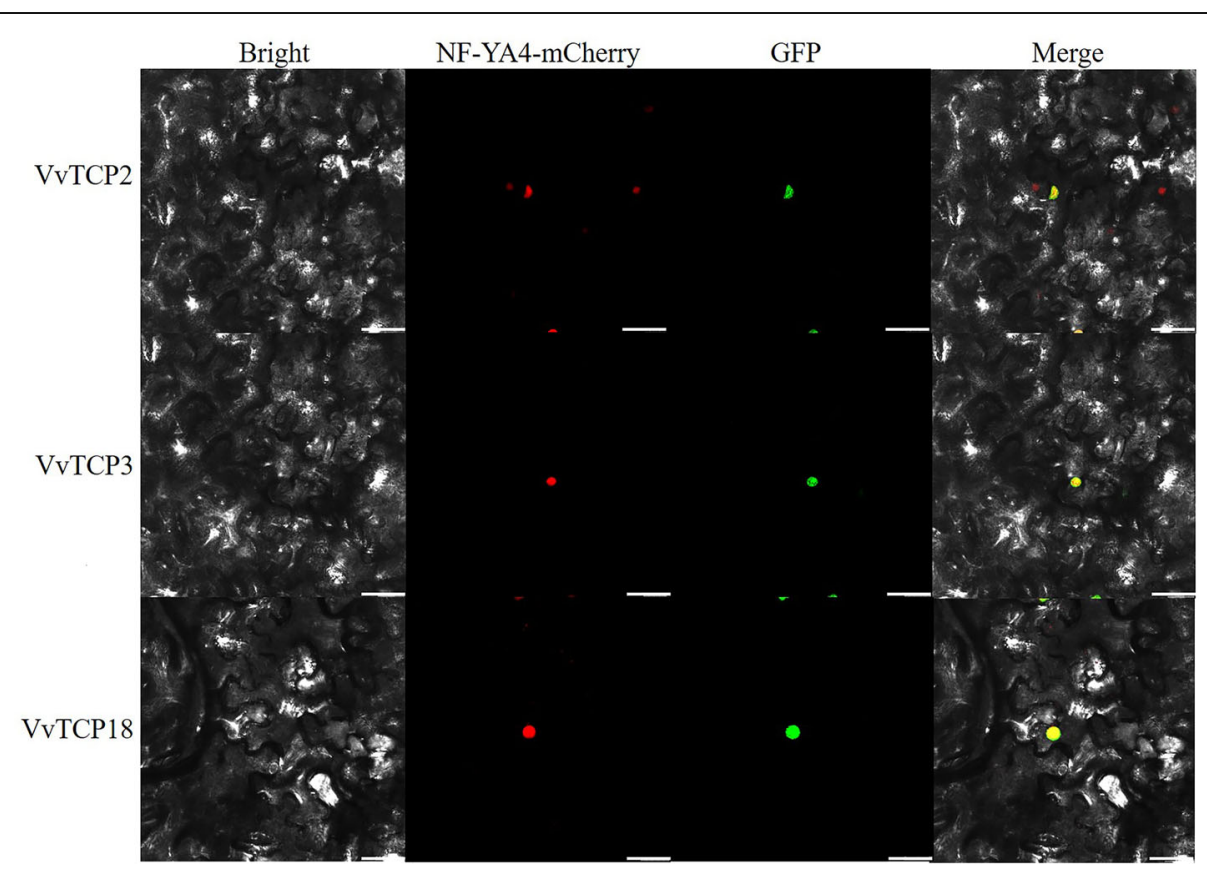

Fig. 10 Subcellular localization of three GFP-fused grapevine TCP proteins. The three VVTCP-GFP fusion proteins (VVTCP2-GFP, VvTCP3-GFP, and VVTCP18-GFP) were transiently expressed in tobacco leaves and observed by confocal microscopy $72 \mathrm{~h}$ later. Nuclei were visualized by cotransformation of a mCherry-labelled nuclear marker (NF-YA4-mCherry). Scale bar, 50 um 
consistent with the prediction results and previous studies in strawberry [31].

\section{Discussion}

The plant-specific TCP transcription factors are known to play important roles in diverse aspects of physiological and biological processes during plant growth and development. To date, the TCP gene family have been investigated and characterized in various plant species such as Arabidopsis [32], tomato [21], apple [33], strawberry [31] and peach [22]. However, virtually no systematic and comprehensive informations of the TCP gene family in grapevine, a nutritious and economically important fruit crop all over the world, have been undertaken. In present study, 18 non-redundant $V v T C P$ genes were identified and analyzed from grapevine genome. Furthermore, we peformed a multi-level analysis of the $V v T C P$ genes in grapevine by investigating their evolutionary relationships, gene structure, protein motifs, duplication events, cis-acting elements, expression profiles in different tissues and developmental stages and under various stress treatment. The systematic characterization of $V v T C P$ genes in grapevine will provide a better foundation for further functional studies of this gene family during grapevine growth and development.

\section{Evolutionary conservation and divergence of the VvTCP gene family in grapevine}

Phylogenetic analysis and sequence alignment showed that all $18 V v T C P$ were classified into three major subgroups, which was consistent with the previous described in Arabidopsis, rice, tomato and strawberry [21, 31, 54]. Each subgroups contained TCP genes from Arabidopsis, rice, tomato, strawberry and grapevine (Fig. 1a). Furthermore, $V v T C P$ members from the same group or subgroup shared a similar motif composition and intron/exon organization. For example, motif 2 and 4 were only present in class I and class II subgroup, respectively (Fig. 3). The consistency of the motif compositions and the exon/intron structures of $V v T C P$ genes further supported the close evolutionary relationships.

In addition, the number of TCP genes was relatively conserved among Arabidopsis (24 members), rice (22 members) and strawberry (19 members) (Fig. 1b). However, it was significantly smaller than that present in tomato (30 members) and apple (52 members), which was consistent with the genome sizes of tomato $(960 \mathrm{Mb})$ [57] and apple (742 Mb) [58], implying that TCP genes in various plants have expanded to different degrees. It is found that many TCP genes in tomato and Arabidopsis had three counterparts in grapevine (Additional file 1: Figure S3 and Additional file 1: Figure S4), indicating that the expansion of TCP family in grapevine may be caused by genome duplication events such as segmental duplication and whole-genome duplication. Our analysis showed that the number of paralogous TCP gene pairs accounted for over $50 \%$ of the entire TCP gene family in grapevine (Fig. 4). The fact supported the view that segmental duplication was a predominant duplication event for TCP genes and the major contributor to the expansion of TCP gene family in grapevine, as described previously, in Arabidopsis and cotton [59].

\section{Functional divergence of $V_{V} T C P$ genes in plant growth and development}

Increasing evidences suggest that TCP gene family involved in a wide range of functions during plant growth and development processes such as in shoot branching, leaf development, flower development and senescence [2]. The expression pattern of $V v T C P$ genes in 42 different grapevine organs/tissues were investigated using an expression atlas of V.vinifera $\mathrm{cv}$ Corvina [45]. The expression analysis indicated that some $V v T C P$ genes can be classified together according to their expression abundant in specific tissues of grapevine, probably reflecting their involved in a common metabolic and/or developmental process.

Previous studies have shown that TCP genes play important roles in leaf senescence and development [60]. In Arabidopsis, five CIN-like subfamily of TCP (AtTCP2, 3, 4, 10 and 24) were targeted by miRNA319 [61]. Ectopic expression of a miR319-insensitive TCP4 (mTCP4) gene led to the formation of miniature leaves during early stages of leaf development [62]. Proper regulation by miR319a of TCP4 was also important for petal and stamen development [14, 63]. Furthermor, overexpression of miR319 or inhibition of multiple CIN-like TCP genes leat to delayed senescence, whereas overexpression of CIN-like TCP genes accelerates leaf senescence by activating biosynthesis of the hormone jasmonic acid [26, 64]. In grapevine, $V v T C P 5, V v T C P 6$ and $V v T C P 18$, the three closest homologs of these Arabidopsis CIN-like genes, had putative binding sites for VvmiR319b (Fig. 2c). VvTCP5 was only relatively high expression level in senescing leaf (Fig. 6), implying its potential function in leaf senescence. VvTCP6 and VvTCP18 were expressed at high levels in young leaf, mature leaf, young inflorescence, bud after burst and burst bud (Fig. 6), which were in agreement with the previous reports that $C I N$-like TCP genes and its post-transcriptional regulator miR319 play pivotal roles in leaf and flower development. These observations suggested that these miRNA-targeted $V v T C P$ genes were likely to perform similar roles in leaf and flower development in grapevine to those of the Arabidopsis homologs.

The CYC/TB1 subgroup is mainly participated in the axillary meristems development [2]. In Arabidopsis, AtTCP1, the most closely homolog of CYC, was involved in the longitudinal elongation of leaves. AtTCP1 was 
strong expression in the petiole, lower portion of the inflorescence stem, and the midrib and distal region of expanding rosette leaves [65]. $V v T C P 10$, which was closely homology with AtTCP1, was transcribed at relatively high levels in young inflorescence, green stem, bud after burst, burst bud or well-developed inflorescence and was almost undetectable in other tested tissues (Fig. 6). This result was partly consistent with the expression profile of AtTCP1 in Arabidopsis, indicating that $V v T C P 10$ might play roles in flower and bud development in grapevine. AtTCP18 acted downstream of auxin and strigolactone to coordinate axillary bud outgrowth and up-regulation of AtTCP18 led to an inhibition of lateral branching. In contrast, mutation of AtTCP18 resulted in an increased number of rosette branches. AtTCP12 displayed a weaker or no mutant phenotype compared with AtTCP18 [9, 66]. The $V v T C P 1$, the homolog of the AtTCP12, was almost undetectable in all tissues, which implied that $V v T C P 1$ was a potential functional redundant TCP member.

By contrast, most Class I genes, which usually play roles in cell growth and proliferation, exhibited more widespread and less tissue-specific expression patterns, such as in leaf, flower, stem and fruit (Fig. 6). These findings suggested that these Class I $V v T C P$ genes might play various regulatory roles at multiple growth and development process. For example, AtTCP14 and AtTCP15 were involved in cell proliferation during seed, leaf and internode development $[12,16]$. AtTCP16 was proposed to modulate early pollen development [20]. AtTCP19 and AtTCP20 negatively regulated the onset of leaf senescence by jasmonate signaling pathway [7, 17]. All of these AtTCP genes had at least one counterpart in grapevine, indicating that Class I TCP in grapevine might share similar functions with Arabidopsis homologs. Taken together, the above-mentioned results from model plants underlined that the TCP family members performed diverse biological functions in multiple plant growth and development processes.

\section{Potential roles of $V v T C P$ genes during berry development and ripening}

Fruit development and ripening is a complex process and requires highly coordinated developmental events which were mainly controlling by a set of TFs regulatory networks [67]. In grapevine, all three genes from $\mathrm{CYC} /$ TB1 subgroup, $V v T C P 1, V v T C P 10$, and $V v T C P 15$ were not expressed in grapevine fruit (Fig. 7a), implying that these three genes in CYC/TB1 subgroup were rarely related to berry development and ripening. Similarly, some SlTCP genes in CYC/TB1 subgroup, such as SlTCP7, SlTCP8, SlTCP9 and SlTCP22, were almost undetectable in fruits [21], indicating that TCP genes in CYC/TB1 subgroup might not be associated with fruit development and ripening in tomato and grapevine. Interesting, the $\mathrm{CYC} / \mathrm{TB} 1$ subgroup genes in strawberry, FvTCP6 and FvTCP14, showed the increased expression during the berry ripening process, and overexpression FvTCP9 transiently by agro-infiltration in strawberry fruits effectively increased the expression levels of ripening-related genes [31], which suggested that they might be involved in strawberry fruit ripening. Taken together, the TCP genes in CYC/TB1 might play variable roles in fruits development and ripening of different species.

Additionally, little was known about the functions of CIN clade members in fruit development. For example, PpTCP.C1 and PpTCP.D1.1 were high transcript accumulation levels in early fruits in peach, but were not associated with fruit ripening, suggesting that these two CIN clade members were likely to be involved in early peach fruit development. In this study, the CIN clade included five TCP members in grapevine, and of these genes, $V v T C P 5$ was not expressed in grapevine fruits, indicating that $V v T C P 5$ was irrelevant to grapevine fruit development and ripening. Moreover, four $V v T C P$ genes in CIN clade was also relatively high expression in early grapevine fruit (Fig. 7), which were generally in agreement with the expression profile of PpTCP.C1 and PpTCP.D1.1 in peach. The similar expression patterns suggested that VvTCP genes in CIN clade was likely to perform roles similar in early fruit development in grapevine.

In tomato, three TCP genes in PCF (class I) subgroup, including SlTCP12, SlTCP15, and SlTCP18, were dominantly expressed in tomato fruits, implying that these TCPs were likely to play important roles during fruit development and ripening [21]. In present study, nine out of ten $V v T C P$ genes in PCF subgroup were down-regulated expression during the berry ripening process, except for $V v T C P 13$ (Fig. 7), indicating that these $V v T C P$ genes might play a regulatory role during the early stages of berry development. Of these nine genes, $V v T C P 7, V v T C P 9$ and $V v T C P 12$ which were individually homologous of SITCP15, SlTCP12 and SlTCP18, might be involved in fruit development, due to the high levels of expression in the developing grapevine fruit (Figs. 7 and 8). In peach, the expression of $P p T C P . A 2$ was negatively correlated to fruit ripening, and silencing of $P p T C P . A 2$ enhanced the expression of PpACS1 and increased ethylene production, indicating that $P p T C P . A 2$ was probably involved in fruit ripening by regulating ethylene biosynthesis [22]. Similarly, the expression of $V v T C P 2$, which was a homologous gene of $P p T C P . A 2$, was consistent with the expression profile of PpTCP.A2 and implied that the $V v T C P 2$ gene was likely to play similar roles to $P p T C P . A 2$ in grapevine fruit development and ripening.

\section{Conclusions}

In conclusion, $18 V v T C P$ genes were identified in the grapevine genome, which were distributed on 11 
chromosomes. These $V v T C P$ genes were divided into two classes based on the phylogenetic and structural feature. A lot of cis-acting elements were observed in the $V v T C P$ promoter sequences, implying that $V v T C P$ gene were controlled by a complex regulatory network. $V v T C P$ genes might play important roles during grapevine growth and development as indicated by their spatial and temporal expression patterns. Notably, most $V v T C P$ genes in grapevine were higher expressed in fruitlets than in other developmental and ripening fruits, indicating that these $V v T C P$ genes were probably involved in early development in grapevine fruit. Taken together, all these findings will lay a solid foundation for for further unraveling the functions of $V v T C P$ genes in grapevine growth and development.

\section{Supplementary information}

Supplementary information accompanies this paper at https://doi.org/10. 1186/s12864-019-6159-2.

Additional file 1: Figure S1. Chromosomal distribution of VVTCP genes Chromosome numbers are provided at the top of each chromosome together with the approximate size. Figure $\mathbf{5 2}$. The conserved protein motifs in the VVTCP proteins. The $x$-axis indicates the conserved sequences of the domain. The height of each letter indicates the conservation of each residue across all proteins. The $y$-axis is a scale of the relative entropy, which reflects the conservation rate of each amino acid. Figure S3. Synteny analysis of TCP genes between Arabidopsis and grapevine. The chromosomes of grapevine and Arabidopsis are depicted as a circle. The approximate distribution of each AtTCP gene and VVTCP gene is marked with a short line on the circle. Red curves denote the details of syntenic regions between grapevine and Arabidopsis TCP genes. Figure S4. Synteny analysis of grapevine and tomato TCP genes. The chromosomes of grape and tomato are depicted as a circle. The approximate distribution of each VVTCP gene and SITCP gene is marked with a short line on the circle. Red curves denote the details of syntenic regions between grapevine and tomato TCP genes.

Additional file 2: Table S1. The primers sequences of VVTCP genes for qRT-PCR and gene cloning.

Additional file 3: Table S2. The synteny regions amony grapevine, Arabidopsis and tomato TCP genes.

Additional file 4: Table S3. Promoter analysis of the grapevineTCP gene family.

Additional file 5: Table S4. Tissue-specific expression patterns of VvTCP genes in grapevine.

Additional file 6: Table S5. Expression profiles of the grapevine VVTCP genes during three fruit developmental stages.

Additional file 7: Table S6. Expression profiles of the grapevine VVTCP genes in response to abiotic stress.

\section{Abbreviations}

bHLH: Basic helix-loop-helix; CNR: Colorless non-ripening; CYC: Cycloidea; GEO: Gene expression omnibus; GFP: Green fluorescent protein; GRAVY: Grand average of hydropathicity; MW: Molecular weight; PCF: Proliferating cell nuclear antigen factor; pl: Isoelectric points; RIN: Ripening inhibitor; RNA-seq: RNA sequencing; RPKM: Reads per kilobase per million mapped reads; TAIR: Arabidopsis information resource; TB1: Teosinte branched1

\section{Acknowledgements}

The authors appreciate those contributors who make related genome and transcriptome datasets accessible in public databases. They would also like to thank reviewers for their careful reading and valuable suggestions.

\section{Authors' contributions}

XP Leng and YB Yuan conceived and supervised this study. XP Leng and HR Wei designed and conducted the experiments and analyzed the data. XZ Xu GS Liu, YZ Wang prepared the plant materials and treated the samples. DJ Jia performed the qRT-PCR experiments. SA Ghuge participated in the data analysis and modified the English. XP Leng and YB Yuan wrote the manuscript. All of the authors have read and approved of the final manuscript.

\section{Funding}

This work was supported by the National Key Research and Development Program of China (2016YFD0400100); the Qingdao People's Livelihood Science and Technology Project (\#18-8-1-428-nsh); the High-level Scientific Research Foundation of Qingdao Agricultural University (No: 665/1118011, 665/1119002) and Shandong Provincial Natural Science Foundation, China (ZR2017YL022).

\section{Availability of data and materials}

Microarray data is available as GEO accession number GSE36128 (http:// www.ncbi.nlm.nih.gov/geo/). RNA-Seq data is available as GEO accession number GSE77218 (https://www.ncbi.nlm.nih.gov/geo/query/acc.cgi), GSE62744 (https://www.ncbi.n/m.nih.gov/geo/query/acc.cgi) and GSE62745 (https://www.ncbi.nlm.nih.gov/geo/query/acc.cgi).

\section{Ethics approval and consent to participate}

Not applicable.

\section{Consent for publication}

Not applicable.

\section{Competing interests}

The authors declare that they have no competing interest.

\section{Author details}

${ }^{1}$ Qingdao Key Lab of Modern Agriculture Quality and Safety Engineering, College of Horticulture, Qingdao Agricultural University, Changcheng Road 700, Qingdao 266109, People's Republic of China. ${ }^{2}$ Institute of Plant Sciences, The Volcani Center, Agricultural Research Organization, 50250 Bet-Dagan, Israel.

Received: 23 May 2019 Accepted: 9 October 2019

Published online: 29 October 2019

\section{References}

1. Cubas P, Lauter N, Doebley J, Coen E. The TCP domain: a motif found in proteins regulating plant growth and development. Plant J. 1999;18:215-22.

2. Martin-Trillo M, Cubas P. TCP genes: a family snapshot ten years later. Trends Plant Sci. 2010;15:31-9.

3. Lopez JA, Sun Y, Blair PB, Mukhtar MS. TCP three-way handshake: linking developmental processes with plant immunity. Trends Plant Sci. 2015;20:238-45.

4. Luo D, Carpenter R, Vincent C, Copsey L, Coen E. Origin of floral asymmetry in Antirrhinum. Nature. 1996;383:794-9.

5. Doebley J, Stec A, Hubbard L. The evolution of apical dominance in maize. Nature. 1997;386:485-8.

6. Kosugi S, Ohashi Y. PCF1 and PCF2 specifically bind to cis elements in the rice proliferating cell nuclear antigen gene. Plant Cell. 1997;9:1607-19.

7. Danisman S, van Dijk AD, Bimbo A, van der Wal F, Hennig L, de Folter S, et al. Analysis of functional redundancies within the Arabidopsis TCP transcription factor family. J Exp Bot. 2013;64(18):5673-85.

8. Navaud O, Dabos P, Carnus E, Tremousaygue D, Herve C. TCP transcription factors predate the emergence of land plants. J Mol Evol. 2007;65:23-33.

9. Aguilar-Martinez JA, Poza-Carrion C, Cubas P. Arabidopsis BRANCHED1 acts as an integrator of branching signals within axillary buds. Plant Cell. 2007;19:458-72.

10. Nicolas M, Rodriguezbuey ML, Francozorrilla JM, Cubas P. A recently evolved alternative splice site in the BRANCHED1a gene controls potato plant architecture. Curr Biol. 2015;25(14):1799-809. 
11. Palatnik JF, Allen E, Wu X, Schommer C, Schwab R, Carrington JC, et al. Control of leaf morphogenesis by microRNAs. Nature. 2003;425:257-63.

12. Kieffer M, Master V, Waites R, Davies B. TCP14 and TCP15 affect internode length and leaf shape in Arabidopsis. Plant J. 2011;68:147-58.

13. Broholm SK, Tahtiharju S, Laitinen RAE, Albert VA, Teeri TH, Elomaa P. A TCP domain transcription factor controls flower type specification along the radial axis of the Gerbera (Asteraceae) inflorescence. Proc Natl Acad Sci U S A. 2008;105(26):9117-22.

14. Nag A, King S, Jack T. miR319a targeting of TCP4 is critical for petal growth and development in Arabidopsis. Proc Natl Acad Sci U S A. 2009;106:22534-9.

15. Tatematsu K, Nakabayashi K, Kamiya Y, Nambara E. Transcription factor AtTCP14 regulates embryonic growth potential during seed germination in Arabidopsis thaliana. Plant J. 2008;53:42-52.

16. Resentini F, Felipo-Benavent A, Colombo L, Blazquez MA, Alabadi D, Masiero S. TCP14 and TCP15 mediate the promotion of seed germination by gibberellins in Arabidopsis thaliana. Mol Plant. 2015;8(3):482-5.

17. Danisman S, van der Wal F, Dhondt S, Waites R, de Folter S, Bimbo A, et al. Arabidopsis class I and class II TCP transcription factors regulate jasmonic acid metabolism and leaf development antagonistically. Plant Physiol. 2012; 159(4):1511-23.

18. Gonzalez-Grandio E, Pajoro A, Franco-Zorrilla JM, Tarancon C, Immink RGH, Cubas P. Abscisic acid signaling is controlled by a BRANCHED1/hd-zip I cascade in Arabidopsis axillary buds. Proc Natl Acad Sci U S A. 2017;114(2):E245-54.

19. Zhou M, Li DY, Li ZG, Hu Q, Yang CH, Zhu LH, et al. Constitutive expression of a miR319 gene alters plant development and enhances salt and drought tolerance in transgenic creeping bentgrass. Plant Physiol. 2013;161:1375-91.

20. Takeda T, Amano K, Ohto MA, Nakamura K, Sato S, Kato T, et al. RNA interference of the Arabidopsis putative transcription factor TCP16 gene results in abortion of early pollen development. Plant Mol Biol. 2006;61:165-77.

21. Parapunova $V$, Busscher $M$, Busscher-Lange J, Lammers M, Karlova R, Bovy $A G$, et al. Identification, cloning and characterization of the tomato TCP transcription factor family. BMC Plant Biol. 2014;14:157.

22. Guo ZH, Shu WS, Cheng HY, Wang GM, Qi K, Zhang SL, et al. Expression analysis of TCP genes in peach reveals an involvement of PpTCP.A2 in ethylene biosynthesis during fruit ripening. Plant Mol Biol Rep. 2018;36:588-95.

23. Pillet J, Yu HW, Chambers AH, Whitaker VM, Folta KM. Identification of candidate flavonoid pathway genes using transcriptome correlation network analysis in ripe strawberry (Fragaria $\times$ ananassa) fruits. J Exp Bot. 2015;66:4455-67.

24. Martin-Trillo M, Grandio EG, Serra F, Marcel F, Rodriquez-Buey ML, Schmitz $\mathrm{G}$, et al. Role of tomato BRANCHED1- like genes in the control of shoot branching. Plant J. 2011;67(4):701-14.

25. Guo Z, Fujioka S, Blancaflor EB, Miao S, Gou X, Li J. TCP1 modulates brassinosteroid biosynthesis by regulating the expression of the key biosynthetic gene DWARF4 in Arabidopsis thaliana. Plant Cell. 2010;22(4):1161-73.

26. Schommer C, Palatnik JF, Aggarwal P, Chételat A, Cubas P, Farmer EE, et al. Control of jasmonate biosynthesis and senescence by miR319 targets. PLoS Biol. 2008;6:e230.

27. Ori N, Cohen AR, Etzioni A, Brand A, Yanai O, Shleizer S, et al. Regulation of LANCEOLATE by miR319 is required for compound-leaf development in tomato. Nat Genet. 2007:39:787-91.

28. Zhou M, Luo H. Role of microRNA319 in creeping bentgrass salinity and drought stress response. Plant Signal Behav. 2014;9:e28700.

29. Li ST, Zachgo S. TCP3 interacts with R2R3-MYB proteins, promotes flavonoid biosynthesis and negatively regulates the auxin response in Arabidopsis thaliana. Plant J. 2013;76:901-3.

30. Koyama T, Furutani M, Tasaka M, Ohme-Takagi M. TCP transcription factors control the morphology of shoot lateral organs via negative regulation of the expression of boundary-specific genes in Arabidopsis. Plant Cell. 2007; 19(2):473-84.

31. Wei W, Hu Y, Cui MY, Han YT, Gao K, Feng JY. Identification and transcript analysis of the TCP transcription factors in the diploid woodland strawberry Fragaria vesca. Front Plant Sci. 2016;7:1937.

32. Riechmann JL, Heard J, Martin G, Reuber L, Jiang CZ, Keddie J, et al. (2000). Arabidopsis transcription factors: genome-wide comparative analysis among eukaryotes. Science. 2000;290:2105-10.

33. Xu R, Sun P, Jia F, Lu L, Li Y, Zhang S, et al. Genome wide analysis of TCP transcription factor gene family in Malus domestica. J Genet. 2014;93:733-46.

34. Liu HL, Wu M, Li F, Gao YM, Chen F, Xiang Y. TCP transcription factors in Moso bamboo (Phyllostachys edulis): genome-wide identification and expression analysis. Front Plant Sci. 2018;9:1263.
35. Huo YZ, Xiong WD, Su KL, Li Y, Yang YW, Fu CX, et al. Genome-wide analysis of the TCP gene family in Switchgrass (Panicum virgatum L.). Int J Genomics. 2019;2019:8514928.

36. Liu MM, Wang MM, Yang J, Wen J, Guo PC, Wu YW, et al. Evolutionary and comparative expression analyses of TCP transcription factor gene family in land plants. Int J Mol Sci. 2019;20(14):3591.

37. Leng XP, Jia HF, Sun X, Shangguan LF, Mu Q, Wang BJ, et al. Comparative transcriptome analysis of grapevine in response to copper stress. Sci Rep. 2015;5:17749.

38. Leng XP, Mu Q, Wang XM, Li XP, Zhu XD, Shangguan LF, et al. Transporters, chaperones, and P-type ATPases controlling grapevine copper homeostasis. Funct Integr Genomics. 2015;15:673-84.

39. Leng XP, Wang PP, Zhao PC, Wang MQ, Cui LW, Shangguan LF, et al. Conservation of microRNA-mediated regulatory networks in response to copper stress in grapevine. Plant Growth Regul. 2017;82:293-304.

40. Hu B, Jin J, Guo YA, Zhang H, Luo J, Gao G. GSDS 2.0: an upgraded gene feature visualization server. Bioinformatics. 2014;31(8):1296.

41. Zhang Y, Mao L, Wang H, Brocker C, Yin XJ, Vasiliou V, et al. Genome-wide identification and analysis of grape aldehyde dehydrogenase (ALDH) gene superfamily. PLoS One. 2012;7:e32153.

42. Wang $Y$, Tang H, Debarry JD, Tan X, Li J, Wang X, et al. MCScanX: a toolkit for detection and evolutionary analysis of gene synteny and collinearity. Nucleic Acids Res. 2012;40(7):e49.

43. Zhao J, Guo RR, Guo CL, Hou HM, Wang XP, Gao H. Evolutionary and expression analyses of the apple basic leucine zipper transcription factor family. Front Plant Sci. 2016;7:376.

44. Postel D, Vanlemmens P, Gode P, Ronco G, Villa P. Plant CARE, a database of plant cis-acting regulatory elements and a portal to tools for in silico analysis of promoter sequences. Nucleic Acids Res. 2002;30:325-7.

45. Fasoli M, DalSanto S, Zenoni S, Tornielli GB, Farina L, Zamboni A, et al. The grapevine expression atlas reveals a deep transcriptome shift driving the entire plant into a maturation program. Plant Cell. 2012;24:3489-505.

46. Saeed Al, Bhagabati NK, Braisted JC, Liang W, Sharov V, Howe EA, et al. TM4 microarray software suite. Method Enzymol. 2006;411:134-93.

47. Shangguan LF, Mu Q, Fang X, Zhang KK, Jia HF, Li XY, et al. RNAsequencing reveals biological networks during table grapevine ('Fujiminori') fruit development. PLoS One. 2017;12(1):e0170571.

48. Massonnet M, Fasoli M, Tornielli GB, Altieri M, Sandri M, Zuccolotto P, et al. Ripening transcriptomic program in red and white grapevine varieties correlates with berry skin anthocyanin accumulation. Plant Physiol. 2017;174:2376-96

49. Haider MS, Zhang C, Kurjogi MM, Pervaiz T, Zheng T, Zhang CB, et al. Insights into grapevine defense response against drought as revealed by biochemical, physiological and RNA-Seq analys. Sci Rep. 2017;7:13134.

50. Guan L, Haider MS, Khan N, Nasim M, Jiu ST, Fiaz M, et al. Transcriptome sequence analysis elaborates a complex defensive mechanism of grapevine (Vitis vinifera L.) in response to salt stress. Int J Mol Sci. 2018;19(12):4019.

51. Zhu XD, Li XP, Jiu ST, Zhang KS, Wang C, et al. Analysis of the regulation networks in grapevine reveals response to waterlogging stress and candidate gene-marker selection for damage severity. R Soc Open Sci. 2019;5:172253.

52. Livak KJ, Schmittgen TD. Analysis of relative gene expression data using real-time quantitative PCR and the 2(-Delta Delta $C(T)$ ) method. Methods. 2001;25:402-8

53. Sparkes IA, Runions J, Kearns A, Hawes C. Rapid, transient expression of fluorescent fusion proteins in tobacco plants and generation of stably transformed plants. Nat Protoc. 2006;1(4):2019-25.

54. Yao X, Ma H, Wang J, Zhang D. Genome-wide comparative analysis and expression pattern of TCP gene families in Arabidopsis thaliana and Oryza sativa. J Integr Plant Biol. 2007;49:885-97.

55. Lin YF, Chen YY, Hsiao YY, Shen CY, Hsu JL, Yeh CM, et al. Genome-wide identification and characterization of TCP genes involved in ovule development of Phalaenopsis equestris. J Exp Bot. 2016;67(17):5051-66.

56. Lei N, Yu X, Li SX, Zeng CY, Zou LP, Liao WB, et al. Phylogeny and expression pattern analysis of TCP transcription factors in cassava seedlings exposed to cold and/or drought stress. Sci Rep. 2017;7:10016.

57. Consortium TG. The tomato genome sequence provides insights into fleshy fruit evolution. Nature. 2012:485(7400):635-41.

58. Velasco R, Zharkikh A, Affourtit J, Dhingra A, Cestaro A, Kalyanaraman A, et al. The genome of the domesticated apple (Malus $\times$ domestica Borkh.). Nat Genet. 2010;42:833-9. 
59. Ma J, Liu F, Wang QL, Wang KB, Jones DC, Zhang BH. Comprehensive analysis of TCP transcription factors and their expression during cotton (Gossypium arboreum) fiber early development. Sci Rep. 2016;6:21535.

60. Schippers JHM. Transcriptional networks in leaf senescence. Curr Opin Plant Biol. 2015;27:77-83.

61. Koyama T, Sato F, Ohme-Takagi M. Roles of miR319 and TCP transcription factors in leaf development. Plant Physiol. 2017;175:874-85.

62. Efroni I, Blum E, Goldshmidt A, Eshed Y. A protracted and dynamic maturation schedule underlies Arabidopsis leaf development. Plant Cell. 2008:20:2293-306.

63. Li J, Wang $Y Z$, Zhang YX, Wang WY, Irish VF, Huang TB. RABBIT EARS regulates the transcription of TCP4 during petal development in Arabidopsis. J Exp Bot. 2016;67:6473-80.

64. Koyama T, Nii H, Mitsuda N, Ohta M, Kitajima S, Ohme-Takagi M, et al. A regulatory cascade involving class II ETHYLENE RESPONSE FACTOR transcriptional repressors operates in the progression of leaf senescence. Plant Physiol. 2013;162:991-1005.

65. Koyama T, Sato F, Ohme-Takagi M. A role of TCP1 in the longitudinal elongation of leaves in Arabidopsis. Biosci Biotechnol Biochem. 2010;74:2145-7.

66. Finlayson S. Arabidopsis TEOSINTE BRANCHED1-LIKE 1 regulates axillary bud outgrowth and is homologous to monocot TEOSINTE BRANCHED1. Plant Cell Physiol. 2007;48:667-77.

67. Karlova R, Chapman N, David K, Angenent GC, Seymour GB, de Maagd RA. Transcriptional control of fleshy fruit development and ripening. J Exp Bot. 2014;65(16):4527-41.

\section{Publisher's Note}

Springer Nature remains neutral with regard to jurisdictional claims in published maps and institutional affiliations.

Ready to submit your research? Choose BMC and benefit from:

- fast, convenient online submission

- thorough peer review by experienced researchers in your field

- rapid publication on acceptance

- support for research data, including large and complex data types

- gold Open Access which fosters wider collaboration and increased citations

- maximum visibility for your research: over $100 \mathrm{M}$ website views per year

At $\mathrm{BMC}$, research is always in progress.

Learn more biomedcentral.com/submissions 